NBSIR 81-2420

\title{
Seasonal Heat Loss Calculation for Slab-On-Grade Floors
}

U.S. DEPARTMENT OF COMMERCE

National Bureau of Standards

Center for Building Technology

Building Physics Division

Washington, DC 20234

March 1982

Snnnsored by:

Department of Energy e of Solar Applications for Buildings nservation and Renewable Energy ington, DC 20585 



\section{SEASONAL HEAT LOSS CALCULATION FOR SLAB-ON-GRADE FLOORS}

T. Kusuda, M. Mizuno, and J. W. Bean

U.S. DEPARTMENT OF COMMERCE

National Bureau of Standards

Center for Building Technology

Building Physics Division

Washington, DC 20234

March 1982

Sponsored by:

U.S. Department of Energy

Office of Solar Applications for Buildings

Conservation and Renewable Energy

Washington, DC 20585

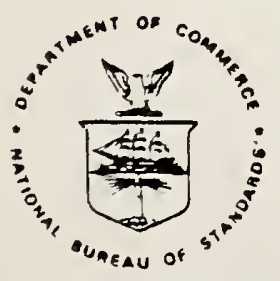

U.S. DEPARTMENT רF COMMERCE, Malcolm Baldrige, Secretary NATIONAL BUREAU OI STANDARDS. Emest Ambler, Director 


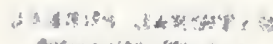

क्weresis

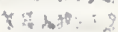

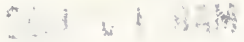




\section{Seasonal Heat Loss Calculation for Slab-on-Grade Floors}

T. Kusuda, M. Mizuno, and J. W. Bean

National Bureau of Standards

\section{Abstract}

In order to facilitate an efficient slab-on-grade heat transfer calculation on a comprehensive energy analysis program such as DOE-2, BLAST AND NBSLD, heat transfer calculations for slab-on-grade floors are reviewed. The computational procedure based on the Lachenbruch method is studied in depth to generate monthly average temperatures at a given depths below the floor slab. The data generated by the Lachenbruch method are then used to develop a simplified procedure for determining the monthly average earth temperatures below the floor slab. These monthly average temperature data can be used for the hourly response factor analysis of floor-slab heat transfer.

Key Words: building heat transfer; DOE-2 Energy Analysis computer program; monthly average earth temperature; thermal response factors. 
LIST OF FIGURES $\ldots \ldots \ldots \ldots \ldots \ldots \ldots \ldots \ldots \ldots \ldots \ldots \ldots \ldots \ldots \ldots \ldots \ldots \ldots \ldots \ldots \ldots \ldots$

NOMENCLATURE $\ldots \ldots \ldots \ldots \ldots \ldots \ldots \ldots \ldots \ldots \ldots \ldots \ldots \ldots \ldots \ldots \ldots \ldots \ldots \ldots \ldots \ldots \ldots \ldots$

CONVERSI ON TO METRIC (SI) UNTTS $\ldots \ldots \ldots \ldots \ldots \ldots \ldots \ldots \ldots \ldots \ldots \ldots \ldots \ldots$ ix

1. INTRODUCTION $\ldots \ldots \ldots \ldots \ldots \ldots \ldots \ldots \ldots \ldots \ldots \ldots \ldots \ldots \ldots \ldots \ldots \ldots \ldots \ldots \ldots \ldots$

2. LACHENBRUCH SOLUTI ON $\ldots \ldots \ldots \ldots \ldots \ldots \ldots \ldots \ldots \ldots \ldots \ldots \ldots \ldots \ldots \ldots \ldots \ldots \ldots . \ldots \ldots$

3. DETERMINATION OF MONTHLY AVERAGE TEMPERATURE FOR BUILDING ENERGY

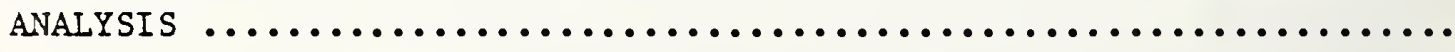

4. GENERAL PROCEDURE FOR ESTIMATING SEASONAL HEAT LOSS FROM THE SLAB-ONGRADE FLOOR

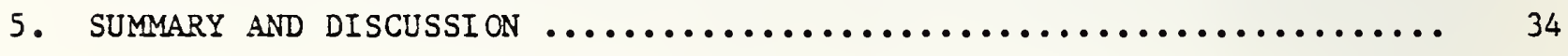

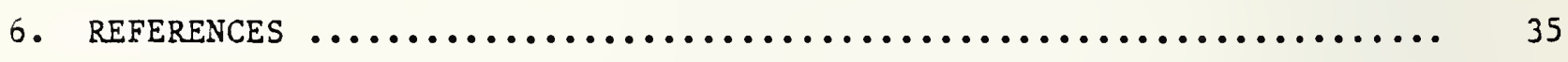

APPENDIX A - Muncey/Spencer Solution $\ldots \ldots \ldots \ldots \ldots \ldots \ldots \ldots \ldots \ldots \ldots \ldots \ldots$ A. 


\section{LIST OF FIGURES}

Page

Figure 1. Boundary condition for heat conduction equation

used by Lachenbruch

Figure 2-1. Calculation algorithms for slab-on-grade problem based

on the superposition of a solution for annular segments ...

Figure 2-2. Approximation of a rectangular region by annular segments .

Figure 3-1. Annual earth temperature expressed in $\left(T-T_{R}\right) / A$ beneath slab-on-grade floor: $\alpha=\left(.93 \mathrm{ft}^{2} / \mathrm{day}\right)$ and $\mathrm{b} / \mathrm{a}=1.5 \ldots \ldots$

Figure 3-2. Annual earth temperature expressed in $\left(T-T_{R}\right) / A$ beneath slab-on-grade floor: $\alpha=(.65 \mathrm{ft} 2 /$ day $), b / a=1.5 \ldots \ldots$.

Figure 3-3. Annual earth temperature expressed in $\left(T-T_{R}\right) / A$ beneath slab-on-grade floor: $\alpha=\left(.93 \mathrm{ft}^{2} /\right.$ day $), b / a=1.0 \ldots \ldots$.

Figure 3-4. Annual earth temperature expressed in $\left(T-T_{R}\right) / A$ beneath slab-on-grade floor: $\alpha=\left(.65 \mathrm{ft}^{2} /\right.$ day $), b / a=1.0 \ldots \ldots$

Figure 4-1. Annual average earth temperature expressed in $\left(T-T_{R}\right)$ / $\left(T_{R}-T_{m}\right)$ beneath the slab-on-grade floor ............. 15

Figure 5-1. Earth temperature-depth profiles at selected distances away from the slab-on-grade floor for $\alpha=\left(.93 \mathrm{ft}^{2} / \mathrm{day}\right) .$.

Figure 5-2. Earth temperature-depth profiles at selected distances away from the slab-on-grade floor for $\alpha=(.65 \mathrm{ft} 2 / \mathrm{day}) .$.

Figure 6-1. Average earth temperature 1 ft below the floor slab

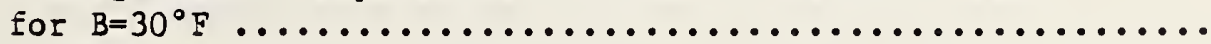

Figure 6-2. Average earth temperature 1 ft below the floor slab

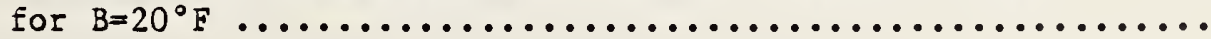

Figure 6-3. Average earth temperature 1 ft below the floor slab

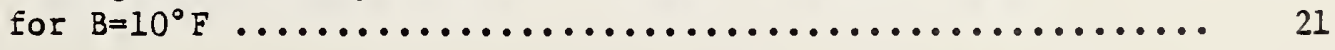

Figure 7-1. Average temperature function under steady-state conditions.

Figure 8-1. Average sub-grade temperature coefficients for the

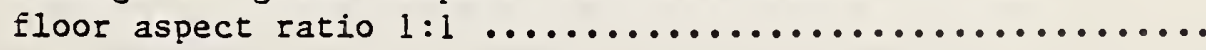

Figure 8-2. Average sub-grade temperature coefficients for the floor aspect ratio $2: 3 \ldots \ldots \ldots \ldots \ldots \ldots \ldots \ldots \ldots \ldots \ldots$ 
Figure 8-3. Average sub-grade temperature coefficients for the

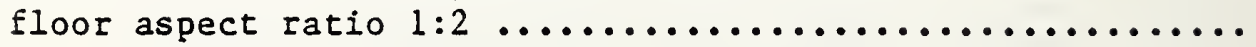

Figure A-1. Muncey/Spencer slab model $\ldots \ldots \ldots \ldots \ldots \ldots \ldots \ldots \ldots \ldots \ldots \ldots$

Figure A-2. Thermal resistance for a square slab of $160 \mathrm{ft}$ perimeter for a ground thermal conductivity of $12 \mathrm{Btu}-\mathrm{in} / \mathrm{h} \cdot \mathrm{ft}{ }^{2}{ }^{\circ} \mathrm{F}$ for various values of edge distance and surface resistance $R_{F} \ldots \ldots \ldots \ldots \ldots \ldots \ldots \ldots \ldots \ldots \ldots \ldots \ldots \ldots$ A 4 .

Figure A-3. Correction factor for non-square slabs .............. A-5 


\section{Nomenclature}

Unless otherwise defined separately in the text, the following standard symbols are used throughout this paper.

$A$

$=T_{R}-T_{M}$

a

= half length of a rectangular slab, ft

b

$=$ half width of a rectangular slab, ft

B

= amplitude of annual cycle of monthly normal outdoor temperature, ${ }^{\circ} \mathrm{F}$

c

= specific heat, Btu/Ibm, ${ }^{\circ} \mathrm{F}$

C

= amplitude of annual indoor temperature cycle, ${ }^{\circ} \mathrm{F}$

$\mathrm{C}_{\mathrm{R}}$

= common ratio of the slab response factors

d

= number of days elapsed after April 1

e

= edge distance, $\mathrm{ft}$

E

$=$ slab heat transfer factor, Btu/h ft

$\mathrm{k}$

$=$ thermal conductivity of soil, Btu/h.ft.F

2

$=$ thickness of soil, ft

$\mathrm{N}$

= number of the slab response factor terms

P

= perimeter length of the slab, ft

= period of temperature cycle, hr

Q

= local floor heat flux, Btu/h. $\mathrm{ft}^{2}$

q

= integrated floor heat loss, Btu/h

R

$=\sqrt{(x-a)^{2}+(y-b)^{2}}$, ft

r

$=\sqrt{R^{2}+z^{2}}$ ft

T

$=$ temperature of a field point, ${ }^{\circ} \mathrm{F}$

$\mathrm{T}_{\mathrm{m}}$

$=$ mean temperature of the annual cycle of the monthly normal outdoor temperature, ${ }^{\circ} \mathrm{F}$

$T_{R}$

= mean temperature of the slab in the building, which is assumed equal to the house temperature, ${ }^{\circ} \mathrm{F}$ 


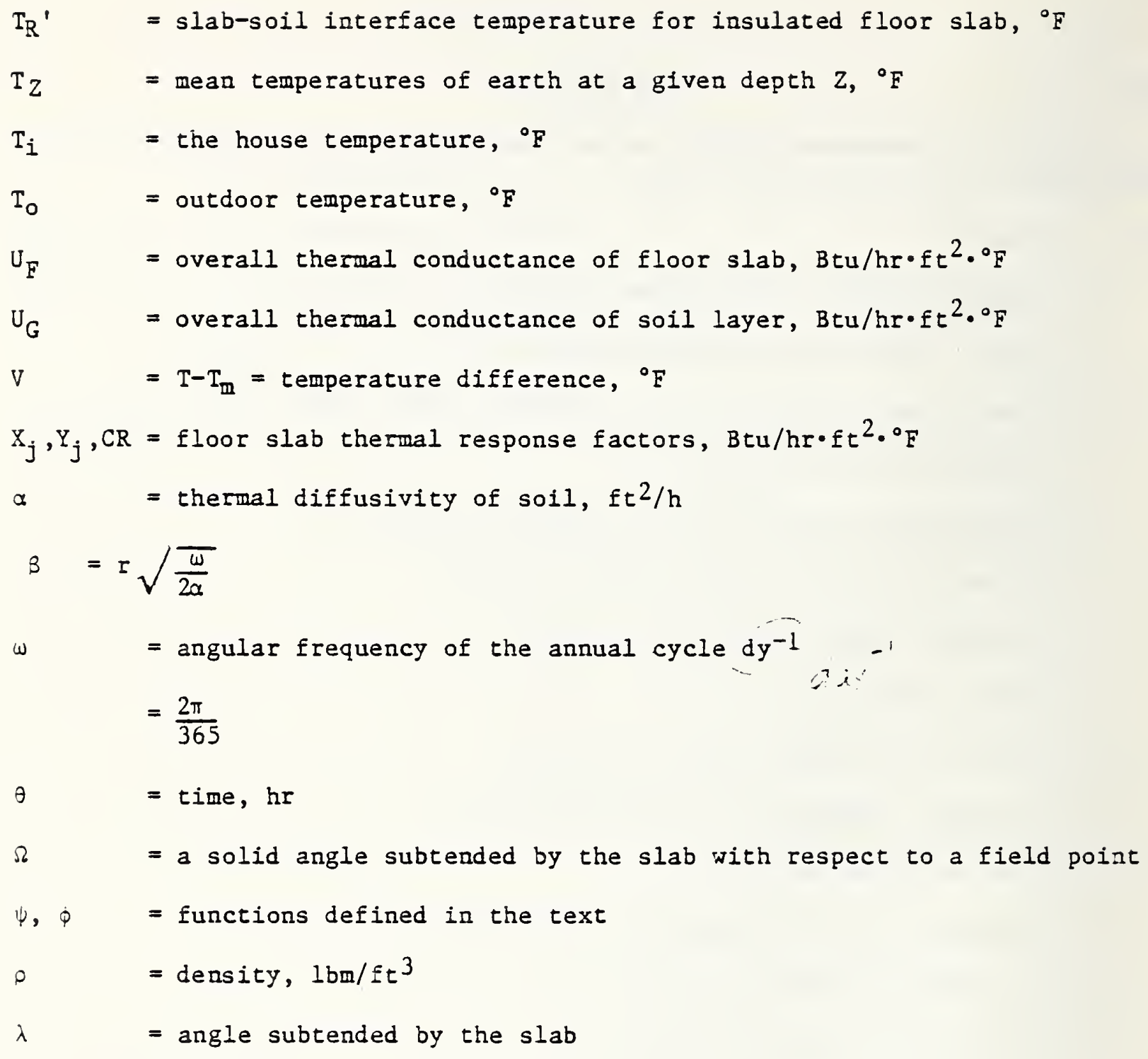


Physical Quantity
To Convert

From To Multiply By

Symbol

Et

m

$3.05 \times 10^{-1}$

A

$f t^{2}$

$\mathrm{m}^{2}$

$9.29 \times 10^{-2}$

$\square$

$f t^{3}$

$\mathrm{m}^{3}$

$2.83 \times 10^{-2}$

$\mathrm{T}$

Fahrenheit

Celsius

$t_{c}=\left(t_{f}-32\right) / 1.8$

$\Delta \mathrm{T}$

Fahrenheit

Kelvin

$\mathrm{K}=\left(\Delta \mathrm{T}_{\mathrm{F}}\right) / 1.8$

p

$1 \mathrm{bm} / \mathrm{ft} \mathrm{t}^{3}$

k

$B t u \cdot i n / h \cdot f t^{2} \cdot f t^{2} \cdot{ }^{\circ} \mathrm{F}$

$\mathrm{kg} / \mathrm{m}^{3}$

16.0

Thermal Conductivity

Thermal Transmittance (or Conductance)

Thermal Resistance

Heat Flux Rate

Heat Flow

Thermal Diffusivity
U

R

$q / A$

$q$

$\alpha$
$\mathrm{Btu} / \mathrm{h} \cdot \mathrm{ft} \mathrm{t}^{\circ} \mathrm{F}$

$h \cdot f t{ }^{2} \cdot{ }^{\circ} \mathrm{F} / \mathrm{B} t \mathrm{u}$

Btu/h

$f t^{2} / h$
$B t u / h \cdot f t^{2}$
$\mathrm{W} / \mathrm{m} \cdot \mathrm{K}$

$1.442 \times 10^{-1}$

$\mathrm{W} / \mathrm{m}^{2} \cdot \mathrm{K}$

5.68

$\mathrm{m}^{2} \cdot \mathrm{K} / \mathrm{W}$

0.176

$\mathrm{W} / \mathrm{m}^{2}$

3.15

W

$2.93 \times 10^{-1}$

$\mathrm{m}^{2} / \mathrm{h}$

$9.29 \times 10^{-2}$ 

Seasonal Heat Loss Calculation for Slab-on-Grade Floors

T. Kusuda, M. Mizuno,* J. W. Bean

\section{INTRODUCTI QN}

Although heat transfer calculations for slab-on-grade floors are a major factor in residential energy analysis, an accurate calculation methodology has not been available. This is because of the complex three-dimensional and time-dependent nature of the heat conduction process involved in the earth-contact building heat transfer process. In addition, there are fundamental questions as to appropriate choices of the thermophysical properties of soil and soil temperature, both of which are by nature not well defined as $f$ ar as the soil around the building is concerned. This is because moisture condition in the soil is constantly changing and affecting the temperature profile as well as the thermal property values. Exact analysis dealing with this simultaneous transfer of heat and moisture is beyond the scope of this paper.

The 1977 ASHRAE Handbook procedure [1] for the slab-on-grade floor heat transfer calculation is simply to use a set of numbers representing the perimeter heat loss coefficient $\mathrm{F}_{2}$ as follows:

$$
q=F_{2} \cdot P \cdot\left(T_{i}-T_{0}\right)
$$

where

$$
\begin{aligned}
q & =\text { floor heat loss } \\
P & =\text { perimeter of exposed edges } \\
T_{i} & =\text { inside air temperature } \\
T_{0} & =\text { outside air temperature }
\end{aligned}
$$

Data for $F_{2}$ are available for the floor with no edge insulation, with 1-inch edge insulation, and 2-inch edge insulation, which are $0.81,0.55$, and 0.50 respectively. These data are derived from the old experimental measurements conducted by the National Bureau of Standards [2] and, separately, by the University of Illinois [3]. It is difficult for building heat transfer analysts to apply these ASHRAE data for general purpose evaluation of a variety of slabon-grade heat losses with respect to sizes, shapes, and physical properties of soils. Moreover, they are valid only under a steady set of test conditions for specific floor types and are not suitable for hourly or seasonal heat transfer calculations.

A conventional approach for the heat transfer analysis of the slab-on-grade problem is to use numerical calculation techniques such as the finite difference and/or finite element solution of the heat conduction equation. Although

* Guest worker from Osaka University, Japan. 
extremely powerful and in many cases the only recourse available for the realworld problem, the three dimensional finite difference solution requires a large number of grid points and lengthy computer time because the heat conduction domain influenced by slab-on-grade structure is extremely large. Moreover, the time span in the order of several years is required before steady annual cycle of ground temperature is achieved. Akasaka [4], for example, used a twodimensional region of $3 \mathrm{~m} \mathrm{x} 6 \mathrm{~m}$ represented by a finite difference grid of $30 \mathrm{x}$ 60 , which required more than 3,000 iterations to obtain a near-steady-state solution. It is doubtful that general design data suitable for three-dimensional heat transfer analysis can be obtained by numerical calculations unless one has access to a large memory, high speed and low cost computing services.

Several authors have, in the past, attempted to develop theoretical bases for estimation of heat loss from slab-on-grade floors, most notable among them being a pioneering work of A. H. Lachenbruch, who used Green's Function [5]. Because of the complexity of the mathematical formulation, Lachenbruch developed an elaborate graphical procedure and demonstrated the procedure for a rectangular slab of $30 \mathrm{ft} \times 100 \mathrm{ft}$. The most striking finding of Lachenbruch's calculation was that it takes more than three years before the temperature beneath the house experiences a steady periodic annual cycle. B. Adamson [6] used the Lachenbruch procedure for a $10 \mathrm{~m} \mathrm{~m} 10 \mathrm{~m} \mathrm{slab}$ and generated the steady periodic annual temperature profiles under the slab-on-grade floors as well as the heat flux along the slab surface.

Adamson's calculations show that the heat flow paths are practically semicircular, with the center of the circle being at the perimeter edge of the slab during the winter season, and they are practically parallel and normal to the slab surface during the summer. Adamson's results also show that the heat flux is practically constant from edge to edge during the sumer, and that an extremely large edge heat loss occurs during the winter.

Admittance and transfer parameters based on the frequency response (Fourier series) solutions were developed by Muncey and Spencer [7]. They developed a method for determining steady-state thermal resistance values of slabs-on-grade of many different shapes, details of which are given in Appendix A. Peavy [8] also analyzed a two-dimensional slab-on-grade problem.

In this report, the Lachenbruch procedure will be extended for generating the monthly average earth temperature beneath the floor slab, which is used in energy analysis simulation programs such as NBSLD, DOE-2 and/or BLAST [8]. The graphic solution method developed by Lachenbruch is converted into an efficient digital computer simulation procedure. The computer program is then used to determine average soil temperatures at a given depth below the floor slab. This average earth temperature below the slab, which is considered constant at least during a month for the hour-by-hour floor heat transfer calculation, has been used in the response factor calculation [9] of the building energy analysis as follows.

$$
Q_{t}=\sum_{j=1}^{N} X_{j} T_{R, t-j}-\sum_{j=1}^{N} Y_{j} T_{R, t-j}+C R \cdot Q_{t-1}
$$


where $Q_{t}=$ hourly floor heat loss at time $t$

$Q_{t-1}=$ hourly floor heat loss at time $t-1$

$X_{j}$ and $Y_{j}$ are thermal response factors predetermined for the floor slab composite and include the thermal resistance at the floor surface

$T_{R, t-j}=$ room temperature above the floor slab at time $t-j$

$T_{k, t-j}^{\prime}=s l a b-s o i l$ interface temperatures at time $t-j$

$\mathrm{CR}=$ common ratio of the floor slab thermal response factors [9]

The value of $T_{k, t-j}$ usually remains unchanged (thus depicted as $T_{k}^{\prime}$ hereafter) for the hour by hour calculation but would vary depending on the season and is dependent upon other parameters such as floor shape, thermal properties and soil.

The rationale of this approach is to interface the hourly simulation of the building floor heat transfer process with the slowly changing earth temperature surrounding the building. It has been a difficult problem to assign an appropriate slab-floor ground temperature $T_{k}^{k}$ for the hour-by-hour slab-floor heat transfer calculation. Various approximations such as an arithmetic average of indoor temperature and well-water temperature, ten-foot-depth average earth temperature, or a monthly average outdoor temperature, have been used in the past simply because of the lack of more appropriate data. Major objective of the paper is then to provide a means to determine improved data for $T_{k}^{k}$. 


\section{LACHENBRUCH SOLUTI ON}

Figure 1 shows the mathematical system of a heated slab (presented by $S$ ) on the ground surface, while the equation below is the basic heat conduction equation and its boundary conditions.

$$
\begin{aligned}
& \frac{\partial^{2} T}{\partial x^{2}}+\frac{\partial^{2} T}{\partial y^{2}}+\frac{\partial^{2} T}{\partial z^{2}}=\frac{1}{\alpha} \frac{\partial T}{\partial \theta} \\
& \text { at } z=0, T=T_{R} \text { on } S \\
& T=T_{m}+B \sin \left(\frac{2 \pi_{\theta}}{\bar{P}}\right) \text { outside } S \\
& z \rightarrow \infty T=T_{m}
\end{aligned}
$$

where

$$
\begin{aligned}
& \mathrm{T}=\text { earth temperature } \\
& \alpha=\text { thermal diffusivity of earth } \\
& \theta=\text { time } \\
& \mathrm{T}_{\mathrm{R}}=\text { room temperature } \\
& \mathrm{T}_{\mathrm{m}}=\text { annual average temperature of earth } \\
& \mathrm{B}=\text { amplitude of annual cycle of monthly average surface temperatures } \\
& \overline{\mathrm{P}}=\text { period of annual temperature cycle }
\end{aligned}
$$

A general solution for equation (1) may be expressed by the Green's Function form as follows:

$$
T(x, y, z, \theta)=\frac{z}{8(\pi \alpha)^{3 / 2}} \int_{0}^{\theta}\left[\iint_{s} \frac{\phi\left(x^{\prime}, y^{\prime}, t\right)}{(\theta-t)^{5 / 2}} e^{\frac{-r^{2}}{4 \alpha(\theta-t)}} d x^{\prime}, d y^{\prime}\right] d t
$$

where $\phi\left(x^{\prime}, y^{\prime}, t\right)=$ temperature distribution over $S$

$$
r=\left[\left(x-x^{\prime}\right)^{2}+\left(y-y^{\prime}\right)^{2}+z^{2}\right]^{1 / 2}
$$

In equation (2), the temperature of the soil under a slab $\mathrm{S}$ is represented by a triple integral with respect to time $t$ and the surface temperature profile $\phi\left(x^{\prime}, y^{\prime}, t\right)$ of the slab $S$. Applying this general solution to a specific boundary condition indicated in figure, 1, Lachenbruch obtained the soil temperature solution in the form of equation ( 3 ). 


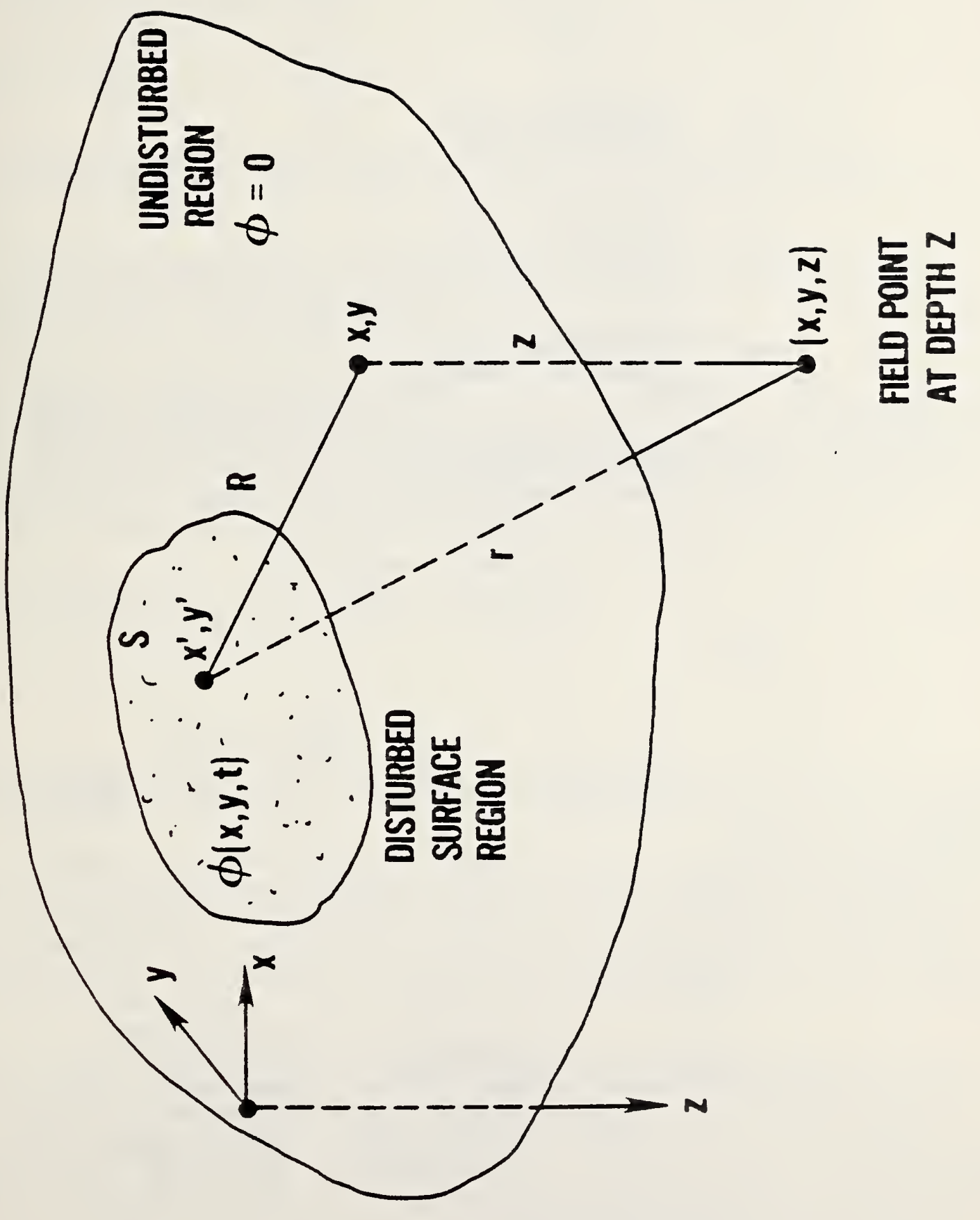

Figure 1. Boundary condition for heat conduction equation used by Lachenbruch 
$T=T_{m}+\left[\frac{T_{R}-T_{m}}{2 \pi}\right] \Omega+B e^{-z \sqrt{\frac{\omega}{2 \alpha}}} \sin \left(\omega \theta-z \sqrt{\frac{\omega}{2 \alpha}}\right)+\frac{B}{2 \pi} \int_{\Omega} \int_{\Omega}(\beta, \theta) d \Omega$

where

$$
\begin{aligned}
& \Omega=\iint_{S} \mathrm{dr}=\iint_{S} \frac{z \mathrm{dx}^{-} \mathrm{dy}^{-}}{\mathrm{r}^{3}} \quad: \text { solid angle subtended by } \mathrm{S} \\
& =\tan ^{-1} \frac{(x+a)(y+b)}{z \sqrt{(x+a)^{2}+(y+b)^{2}+z^{2}}} \\
& -\tan ^{-1} \frac{(x-a)(y+b)}{z \sqrt{(x-a)^{2}+(y+b)^{2}+z^{2}}} \\
& -\tan ^{-1} \frac{(x+a)(y-b)}{z \sqrt{(x+a)^{2}+(y-b)^{2}+z^{2}}} \\
& \tan ^{-1} \frac{(x-a)(y-b)}{z \sqrt{(x-a)^{2}+(y-b)^{2}+z^{2}}} \\
& \psi(\beta, \theta)=e^{-\beta\{(1+\beta) \sin (\omega \theta-\beta)+\beta \cos (\omega \theta-\beta)\}} \\
& \beta=r \sqrt{\frac{\omega}{2 \alpha}} \\
& \omega=\frac{2 \pi}{P}
\end{aligned}
$$

Differentiating equation (3) with respect to $z$, the surface heat flux may be obtained as follows:

$$
\begin{aligned}
& Q(x, y, o, \theta)=-k_{\left(\frac{d T}{d z}\right)} z=0 \\
& =k \sqrt{\frac{\pi}{2 \alpha}} B(\sin \omega \theta+\cos \omega \theta) \\
& +\frac{k}{2 \pi}\left(T_{R}-T_{m}\right)\left\{\frac{\sqrt{(x+a)^{2}+(y+b)^{2}}}{(x+a)} \frac{\sqrt{(x+a)^{2}+(y+b)^{2}}}{(x-a)}\right. \\
& -\frac{{\sqrt{(x+a)^{2}+(y-b)^{2}}}^{2}}{(x+a)}+\frac{\sqrt{(x-a)^{2}+(y-b)^{2}}}{(x-a)} \frac{\frac{1}{(y-b)}^{(y-b)}}{(x-a)} \\
& -\frac{k}{2 \pi}^{B} \iint_{S} \frac{\psi\left(B_{O}, \theta\right) d S}{R_{0}{ }^{3}}
\end{aligned}
$$




$$
\text { where } \begin{aligned}
& \beta_{0}=R_{0} \sqrt{\frac{\omega}{2 a}} \\
& R_{0}=\sqrt{(x-a)^{2}+(y-b)^{2}} \\
& d s=d x^{\prime} d y^{\prime} \\
& q=\frac{1}{s} \iint_{s} Q d x^{\prime} d y^{\prime}
\end{aligned}
$$

Since the major purpose of this paper is to determine the average earth temperature below the floor slab, only the evaluation of equation ( 3 ) will be discussed.

In order to evaluate equation ( 3 ), however, it is necessary to perform the integration of $\psi(\beta, \theta)$ over an entire solid angle $\Omega$ subtended by the surface slab with respect to a given field point $(x, y, z)$.

Figures 2-1 and 2-2 show a scheme to evaluate this integral by a superposition of annular segments emanating from a point $(x, y)$ in the ground. The scheme was originally devieloped by Lachenbruch on the basis that analytical integration of $\psi(\beta, \theta)$ is available for an annular region between radii $R_{i}$ and $R_{i-1}$ emanating from a point $x, y, z$. Equation (5) shows a general form of the integration using the-superposition of segments of annular region solutions.

$$
\underset{2 \pi}{B} \int_{\Omega} \psi(B, \theta) \mathrm{d} \Omega={ }_{2 \pi} \sum_{i=1}^{\infty} \lambda_{i}\left\{\phi\left(R_{i}\right)-\phi\left(R_{i-1}\right)\right\}
$$

where

$$
\phi(R)=\frac{z}{\sqrt{z^{2}+R^{2}}} e^{\sqrt{z^{2}+R^{2}} \sqrt{\frac{D}{2 \alpha}}} \quad \sin \left(\omega \theta-\sqrt{z^{2+} R^{2}} \sqrt{\frac{\omega}{2 \alpha}}\right) .
$$

Although it requires a relatively large number of annular spaces of fine width over the slab, this scheme is extremely efficient for covering a large area outside the building where the angular effect ( $\lambda$ = central angle substantiated by the slab boundary with respect to a projected point in question) vanishes, as the annular region is extended beyond the slab. The value $\phi(R)$ also vanishes quickly as $\mathrm{R}$ becomes large.

An efficient computer program has been developed to determine monthly earth temperature profile under heated slabs of different shapes and different temperatures. Figures 3-1 through 3-4 show results of sample calculations where depth isotherms across the floor center line are indicated in terms of ratio of $T-T_{m}$ with respect to $T_{R}-T_{m}$ of equation (3). In these figures, the amplitude of the monthly average outdoor air temperature $B$ are chosen to be 1.0 and 1.5 of $\left(T_{R}-T_{m}\right)$. The subject floor is $20 \mathrm{ft}$ square and thermal diffusivity of soil is also varied to cover from 0.027 and $0.039 \mathrm{ft} / \mathrm{hr}$, which represent average and wet soil conditions respectively. 
It is interesting to note that:

1. Earth temperature outside the region directly below the floor is also affected as far as one house width.

2. A large temperature gradient exists near the floor edge during the winter months.

3. Summer heat transfer is practically one-dimensional and normal to the floor slab without having much of the edge heat flow phenomena of winter.

4. Earth temperature disturbance extends beyond $30 \mathrm{ft}$ depth.

Figure 4 is the annual average earth temperature beneath the slab, which represents the second or the steady-state heat conduction term of equation ( 3 ).

The zero temperature region indicated in figure 4 is the annual average temperature of undisturbed earth, which is numerically equal to $\mathrm{T}_{\mathrm{m}}$. Figures 5-1 and 5-2 show the monthly earth temperatures with respect to depth at selected distances away from the building for wet and average soil conditions and for the temperature amplitudes of 1.0 and $1.5\left(T_{R}-T_{m}\right)$. These figures show that the annual cycle of the earth temperatures is not significantly affected even at a point as close as $5 \mathrm{ft}$ away from the building. 


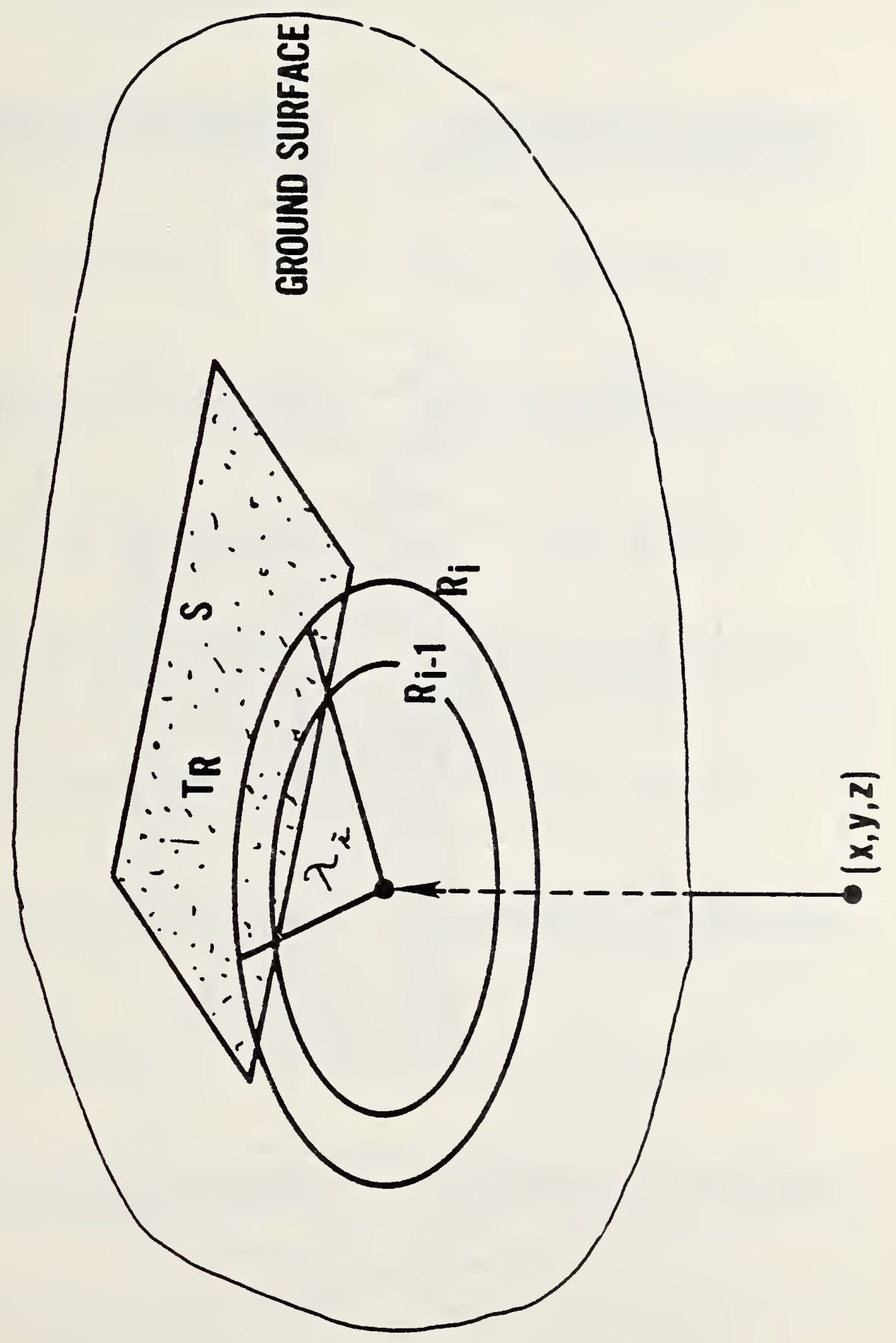

Figure 2-1. Calculation algorithms for slab-on grade problem based on the superposition of a solution for annular segments 


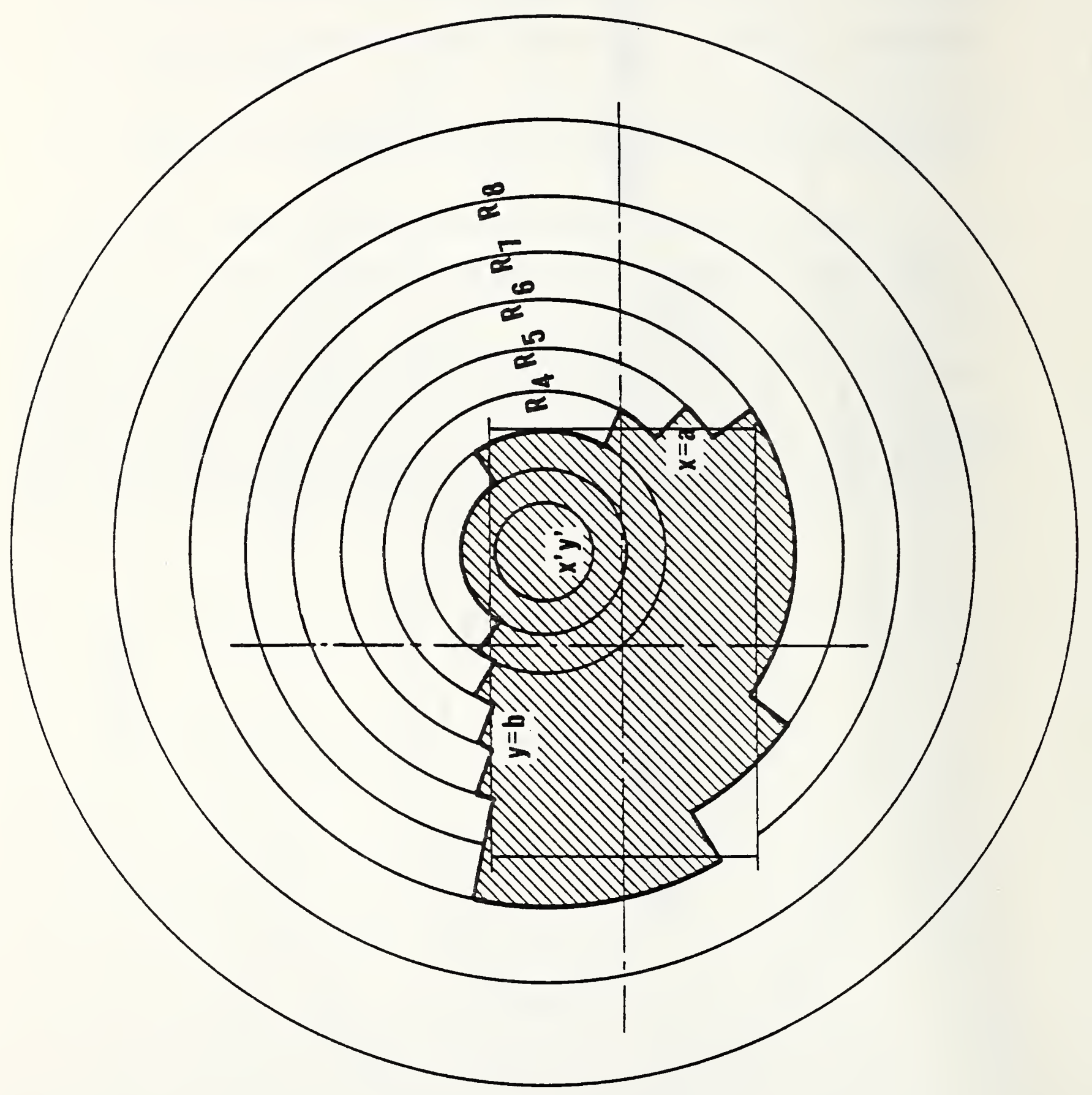

Figure 2-2. "mation of a rectangular region by annular segments 

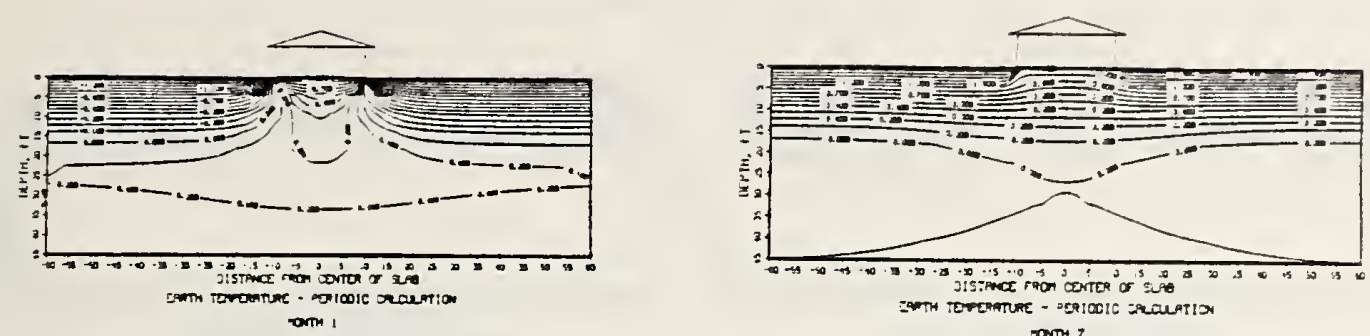
ram 1
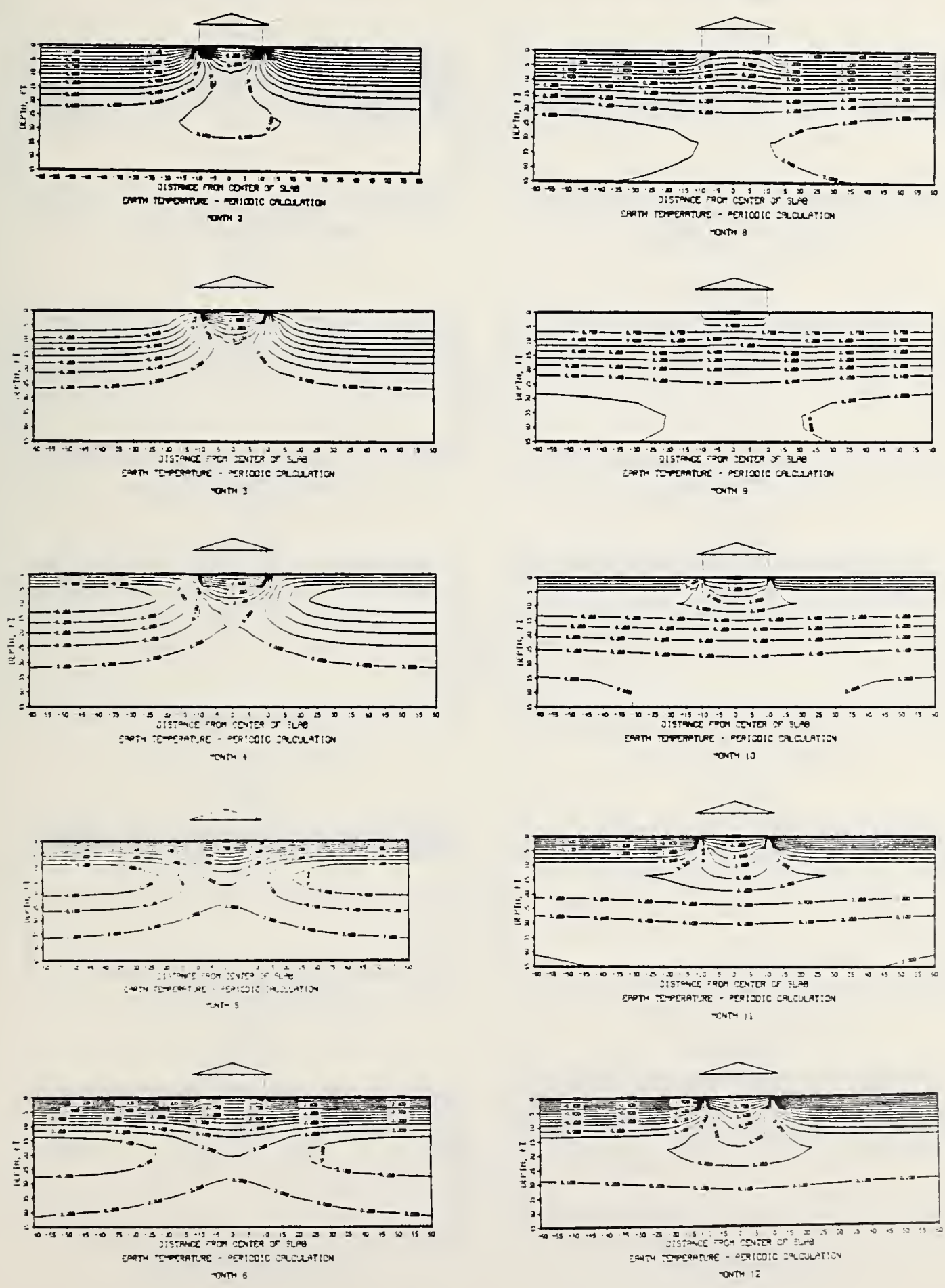

Figure 3-1. Annual earth temperature expressed in $\left(T-T_{R}\right) / A$ beneath slab-on-grade floor; $\alpha=\left(.93 \mathrm{ft}^{2} / \mathrm{day}\right)$ and $b / a=1.5$ 

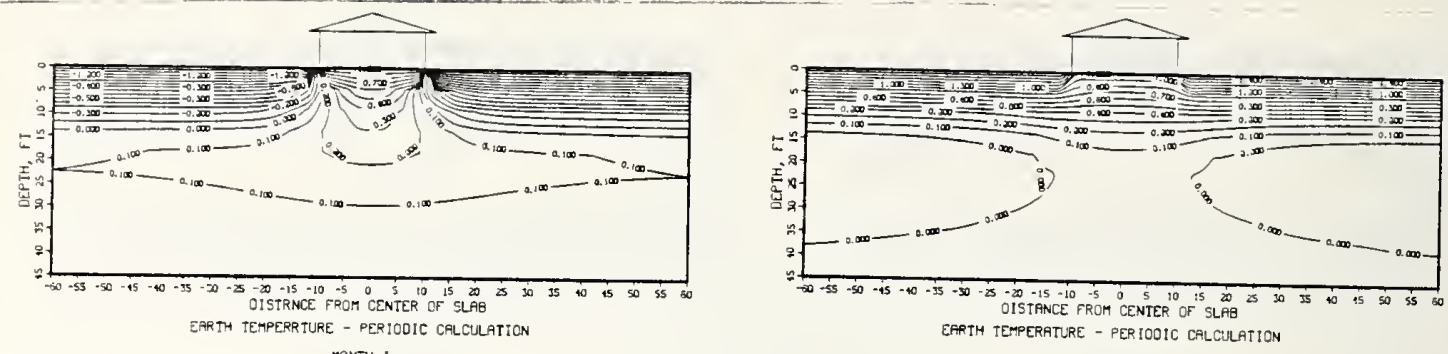
MONTH I

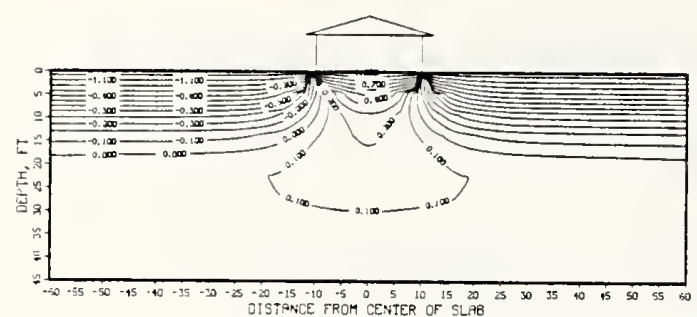
ERRTM TEMPERRTURE - PERICOIC CFLCULRTION MONTH 2 EARTH TEMPERATURE - PERIOOIC CALCULATION

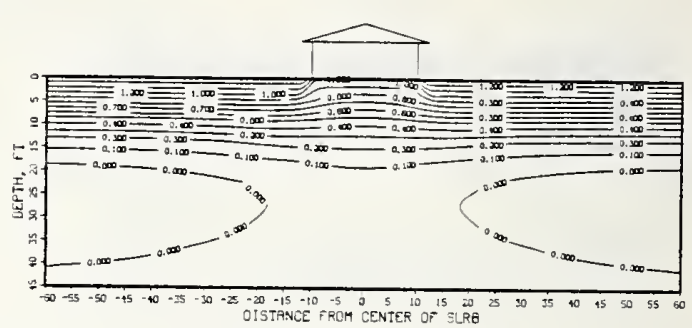
ERRTH TEMPERRTURE - PERIOOIC CALCULATION MONTH E

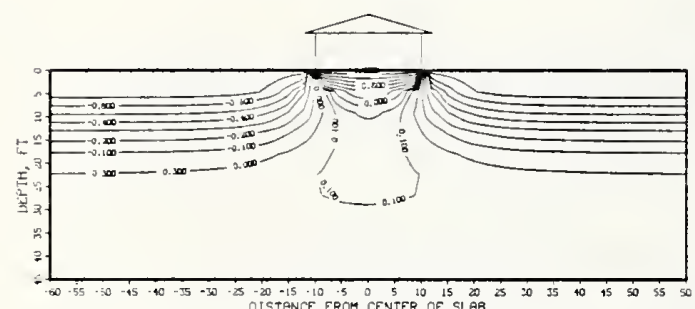
OISTANCE FROM CENTER OF SLAB
EARTH TEMPERATURE - PERIOOIC CRLCULRTION MONTH 3

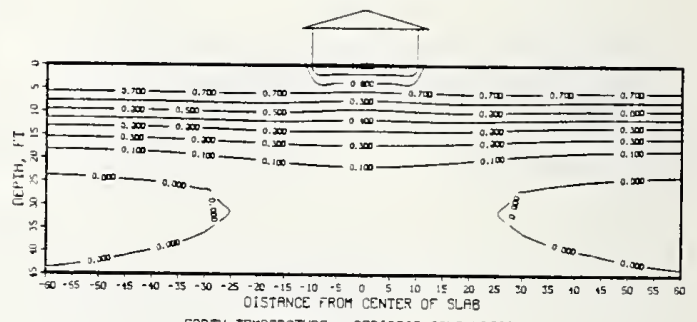
EARTH TEMPERATURE - PERIODIC CALCULRTION

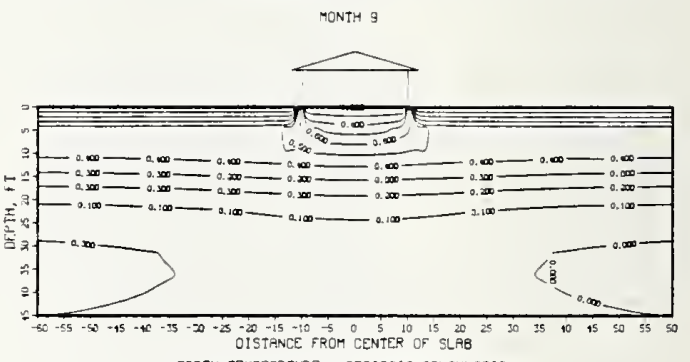
EARTH TEMPERR TURE - PERIOOIC CALCULATION EARTH TEMPERRTURE - PERIOOIC CFLCULATION MONTH 10

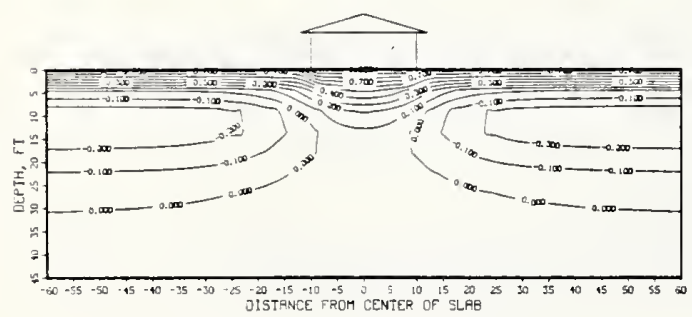
EARTM TEMPERATURE - PERIOOIC CALCULATION MONTH S
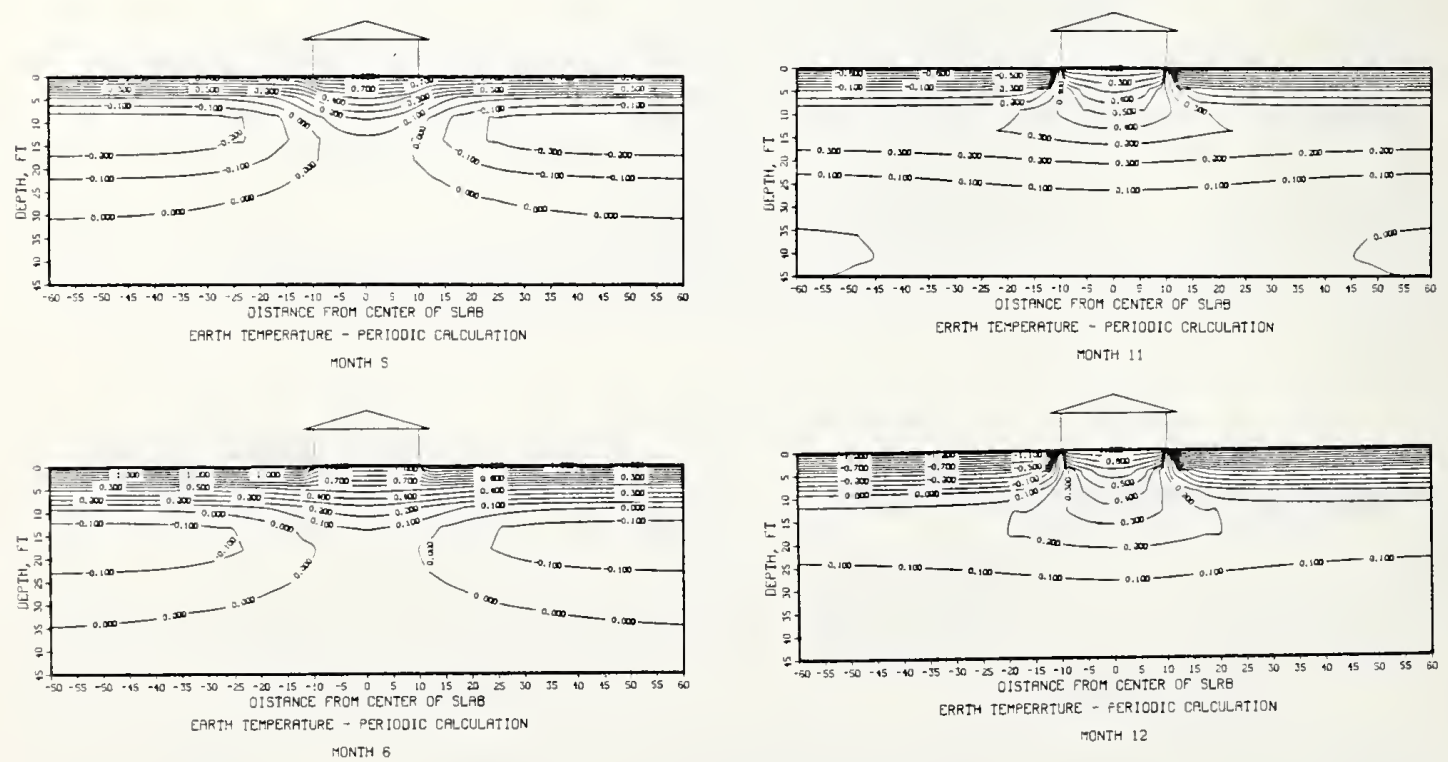
ERRTH IEMPERATURE - PERIOOIC CRLCULATION

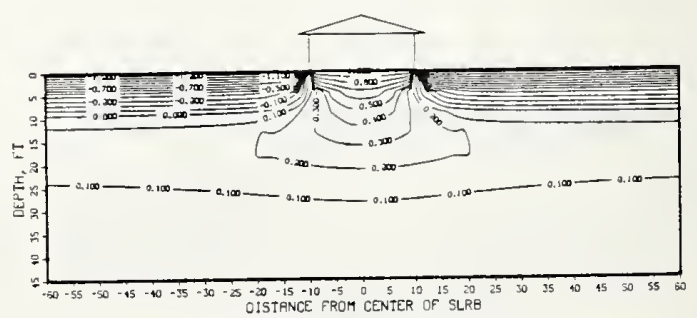
ERRTH TEMPERRTURE - FERIODIC CRLCULATION MONTH 12

Figure 3-2. Annual earth temperature expressed in $\left(T-T_{R}\right) / A$ beneath slab-on-grade floor: $\alpha=\left(.65 \mathrm{ft}^{2} /\right.$ day $), \mathrm{b} / \mathrm{a}=1.5$ 

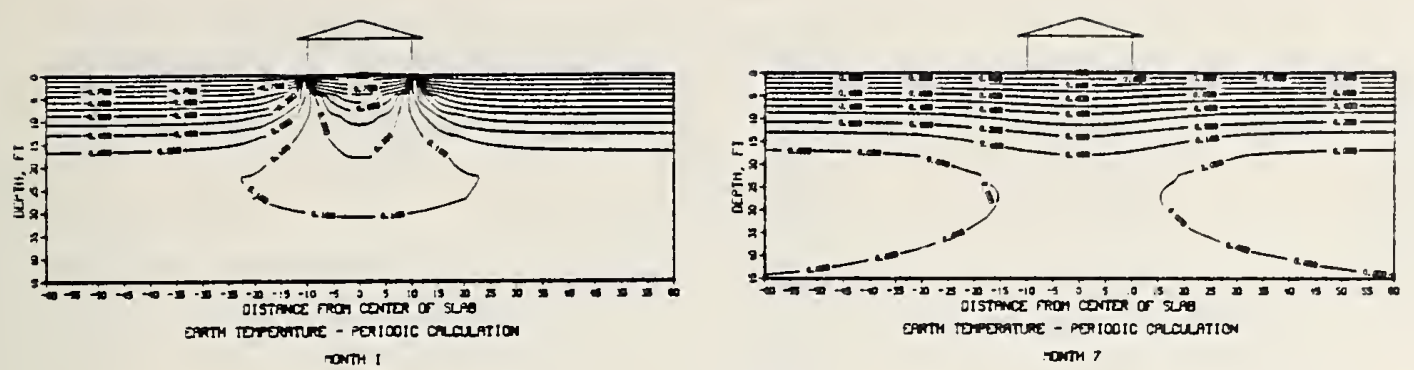
rown I

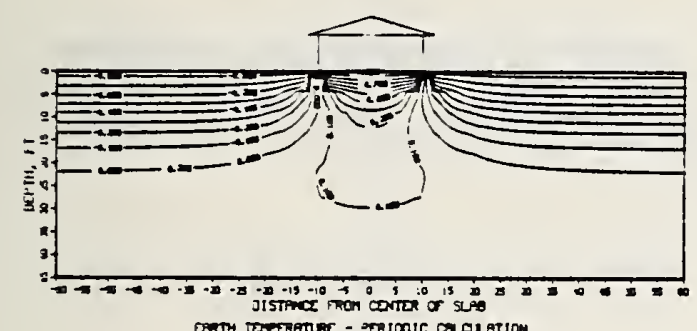

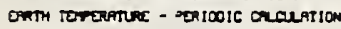

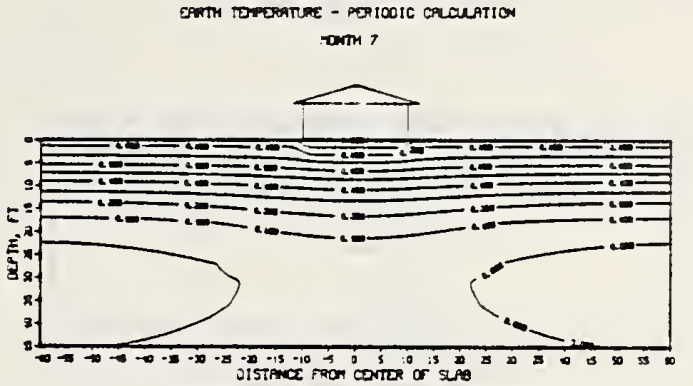

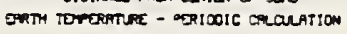
TONTH a

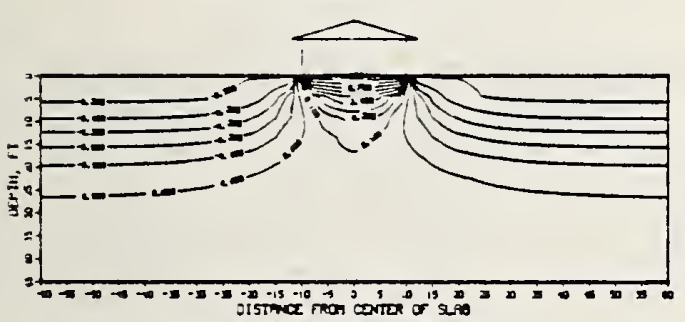

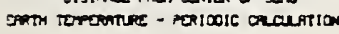
ront 3

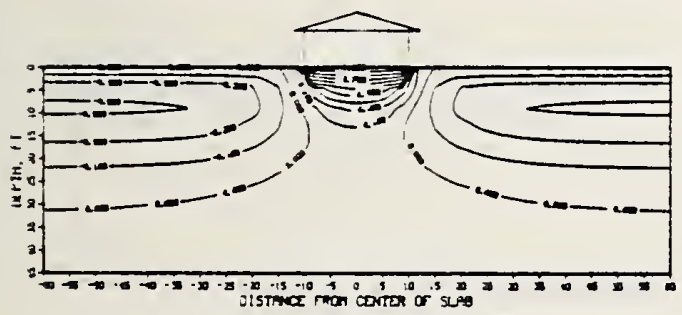

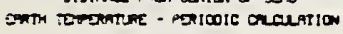
Tant 4

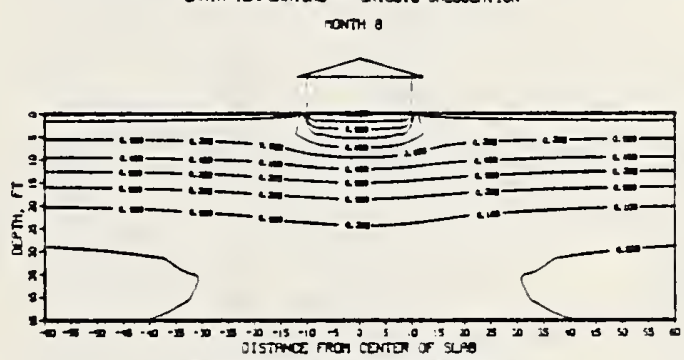
orta toreature - pertocte crecuation

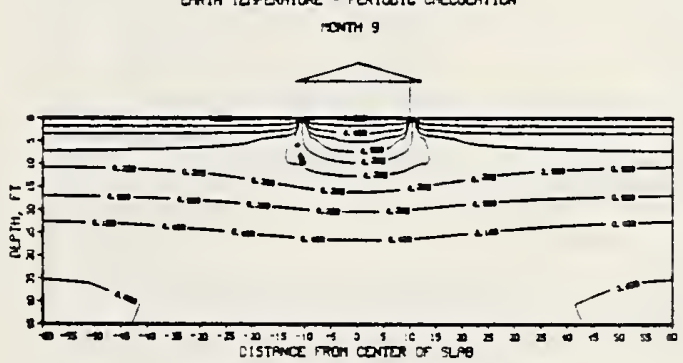
ontr tercature - avilcoic crlaction rowtit 10

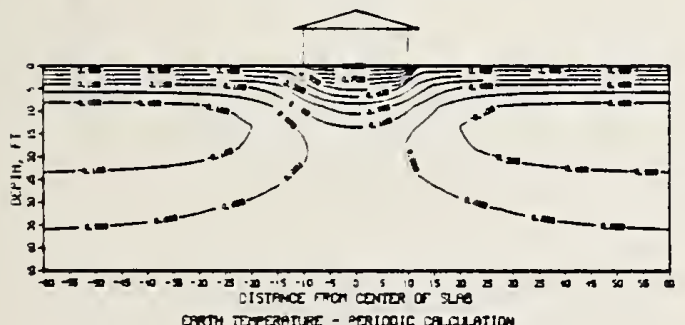

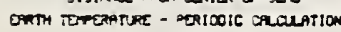
mons 5
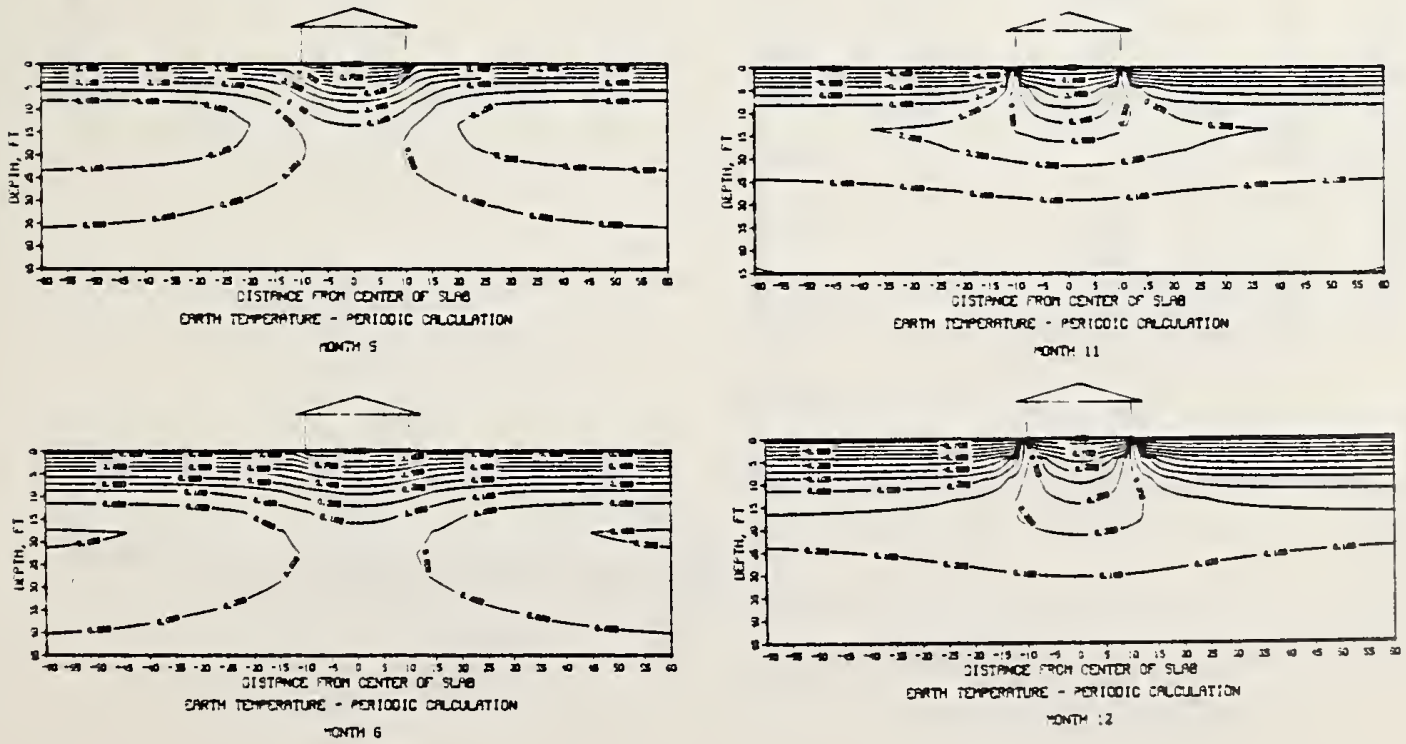

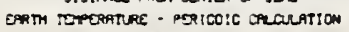
arts 11

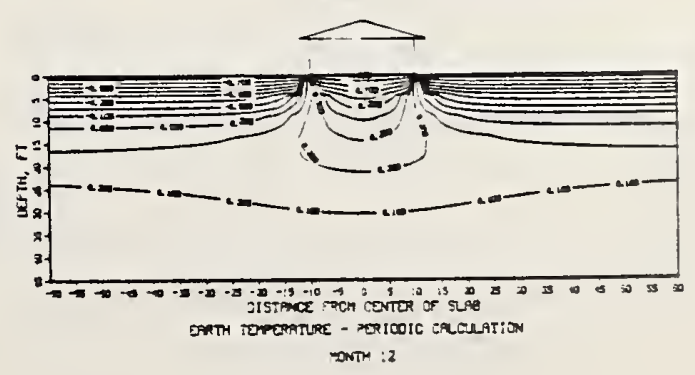

Figure 3-3. Annual earth temperature expressed in $\left(T-T_{R}\right) / A$ beneath slab-on-grade floor: $\alpha=(.93 \mathrm{ft} 2 /$ day $), b / a=1.0$ 


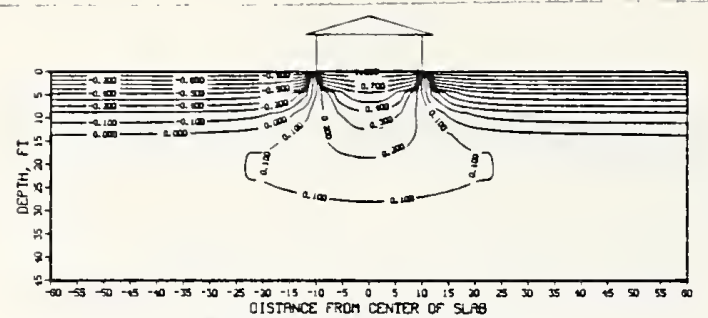
ERRTH TUPERATURE - PERIOOIC CRLCLLATION
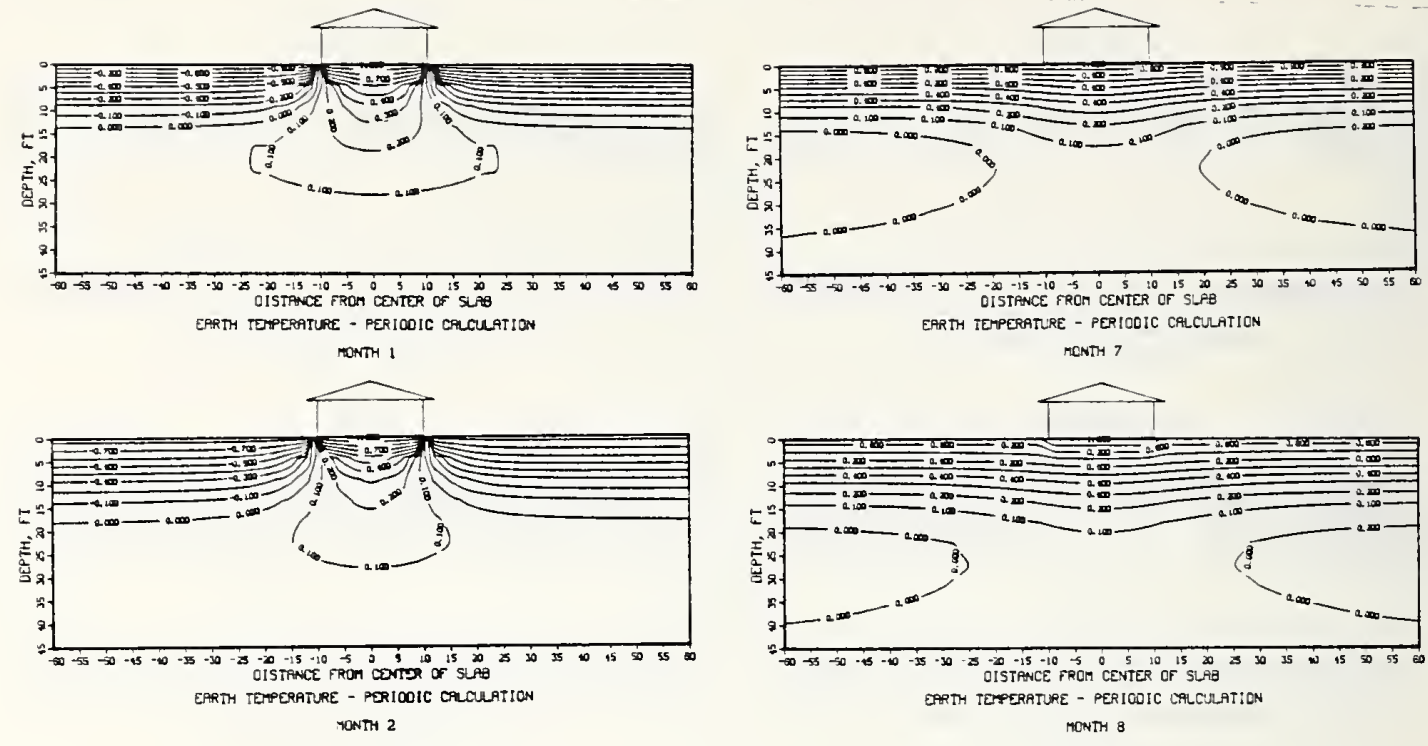
EARTH TEMPERATURE - PERIOCIC CALCULATION

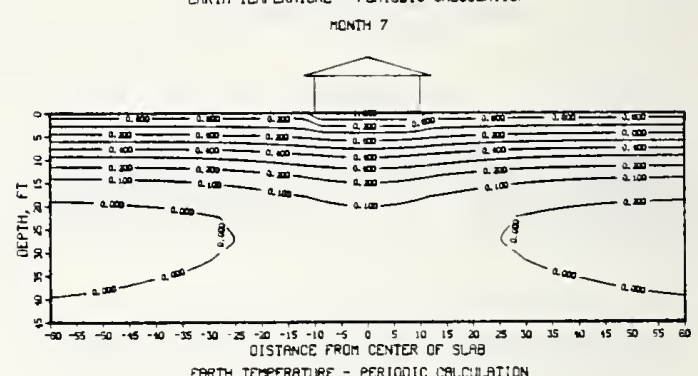
EARTH TETERATURE - PERIODIC CALCULATION MONTM 8

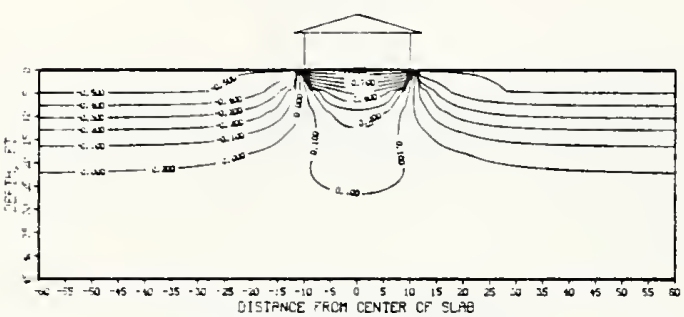
raftM TEMPERATUKE - PERICDIC CALCULATICN MONTH 3

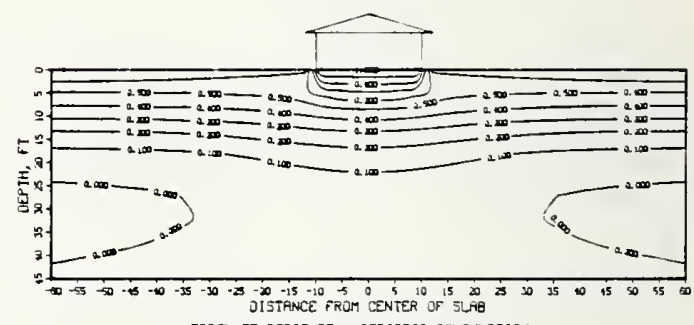
Earth tempERATIJRE - PERIOOIC CALCULATION

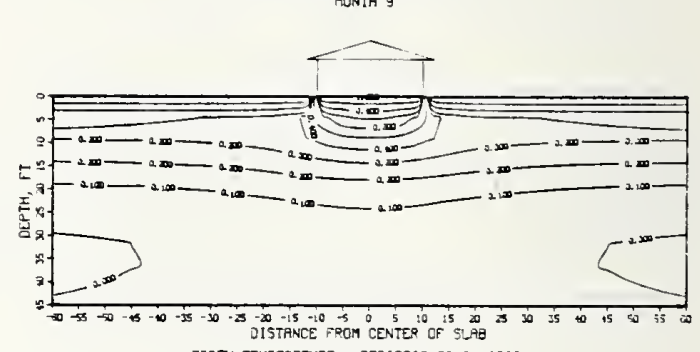
EARTH TEMPERATURE - PERIOOIC CALCULATION EARTM TEMTERATURE - PERICDIC CALCULATION MONTH 4

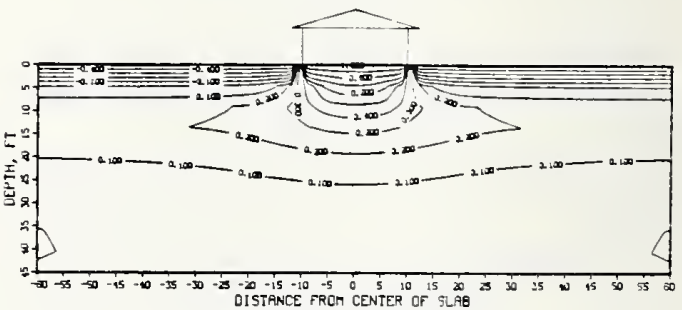
EARTM TETPERATURE - PERIOCIC CRLCULATION EARTH TEMPERRTUPE - PERTOOIC CRLCTLATION MantT $S$
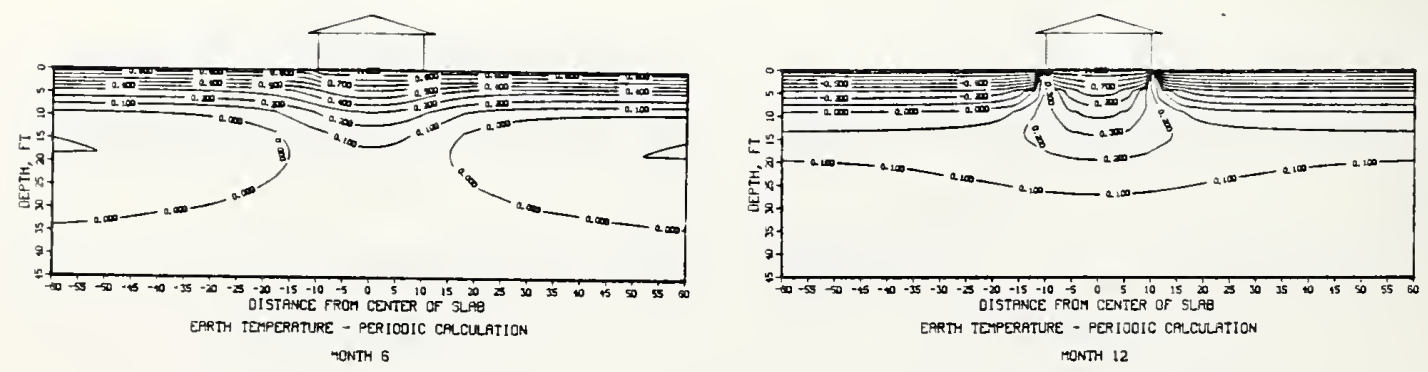

Figure 3-4. Annual earth temperature expressed in $\left(T-T_{R}\right) / A$ beneath slab-on-grade floor: $\alpha=\left(.65 \mathrm{ft}^{2} / \mathrm{day}\right), \mathrm{b} / \mathrm{a}=1.0$ 


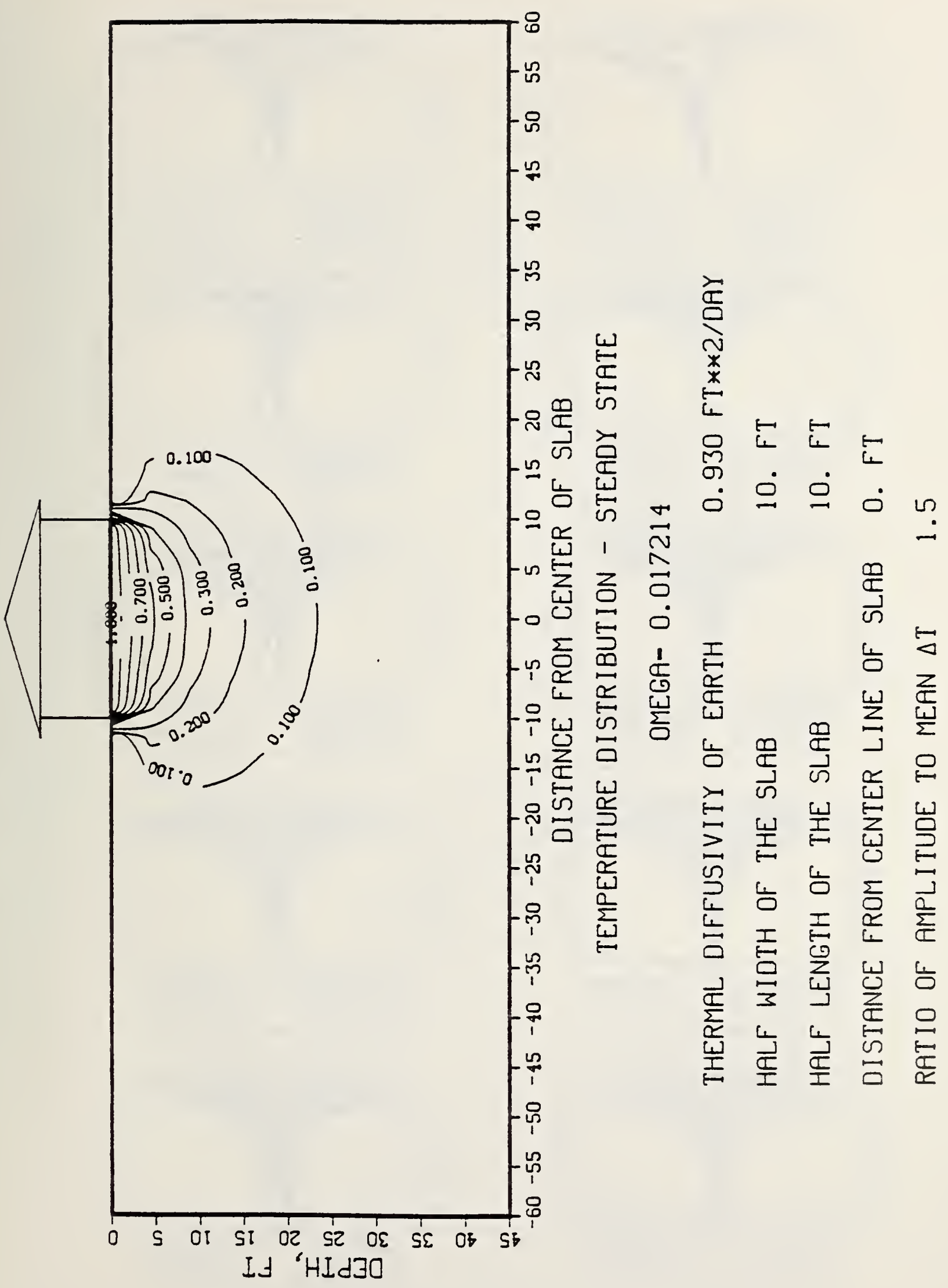

Figure 4-1. Annual average earth temperature expressed in $\left.\left(T-T_{R}\right) / T_{R}-T_{M}\right)$ beneath the slab-on-grade floor 

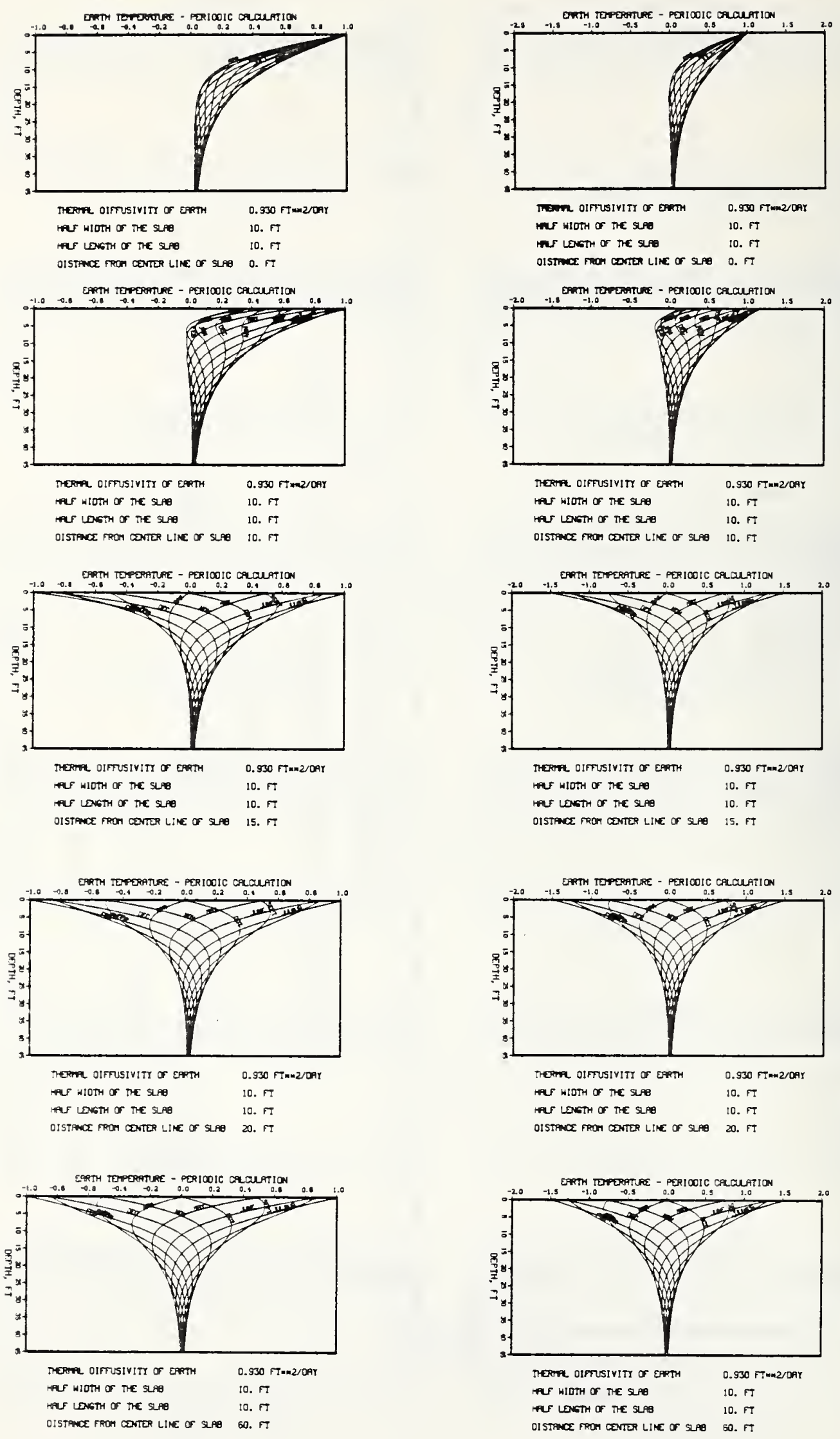

Figure 5-1. Earth temperature-depth profiles at selected distances away from the slab-on-grade floor: $\alpha=\left(.93 \mathrm{ft}^{2} / \mathrm{day}\right)$ 

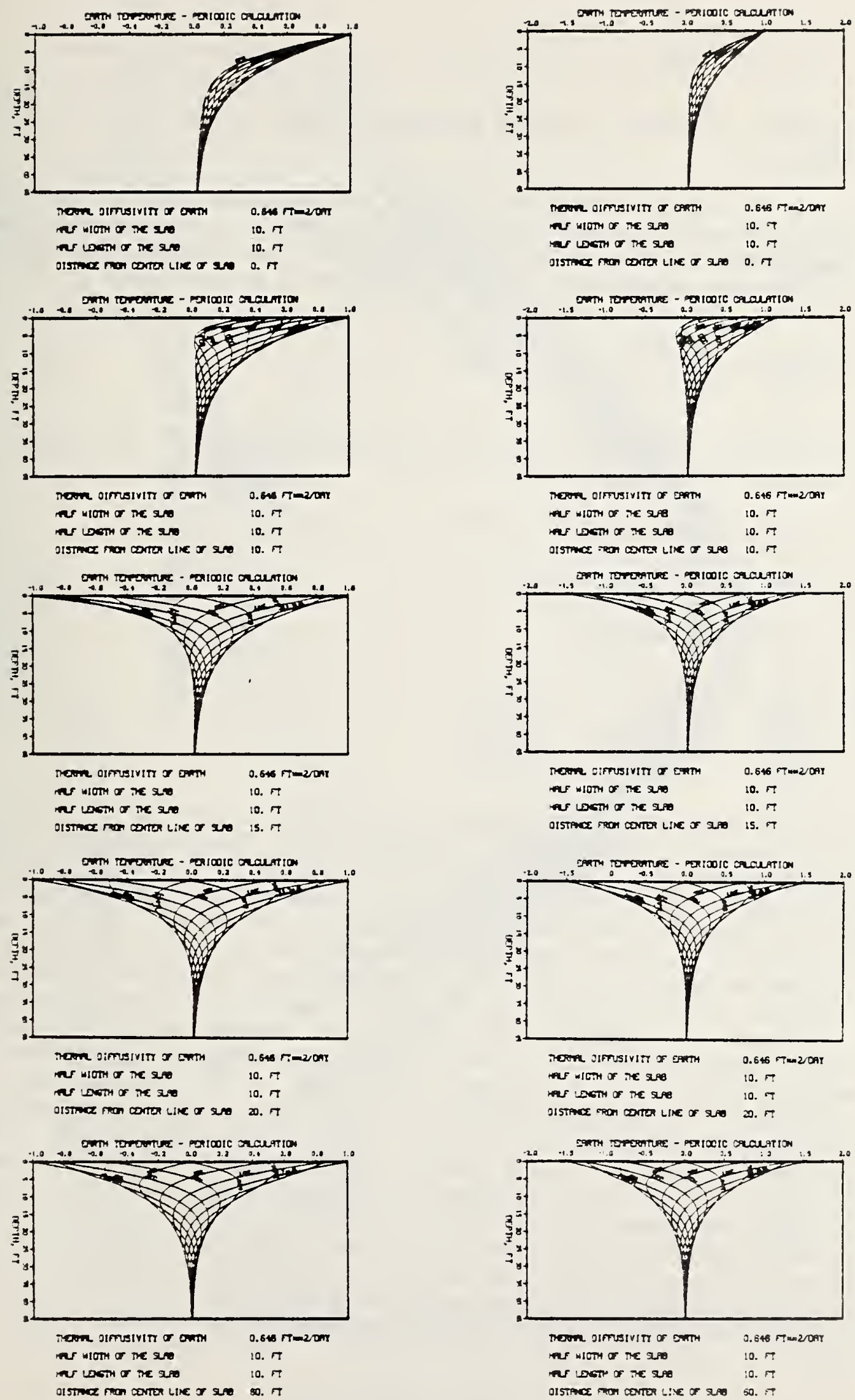

Figure 5-2. Earth temperature-depth profiles at selected distances away from the slab-on-grade floor for $\alpha=\left(.65 \mathrm{ft}^{2} /\right.$ day $)$ 
3. DETERMINATION OF MONTHLY AND AREA AVERAGE TEMPERATURE FOR BUILDING ENERGY ANALYSIS

In order to use the solution thus obtained in the previous sections for the floor-slab heat transfer calculation, the monthly and area average earth temperature $z$ ft below the floor slab is needed. The data are obtained by integrating the earth temperature beneath the slab area in such a manner that

$$
\overrightarrow{\mathrm{T}}_{(z)}=\frac{1}{\mathrm{~b}} \int_{0}^{a} \int_{0}^{b} \mathrm{~T}(\mathrm{x}, \mathrm{y}, z) \mathrm{dxdy}
$$

The data for $\overline{\mathrm{T}}(z)$ are obtained for several selected values for $\alpha, T_{R}-T_{\text {m }}, B$, a and $b$, such as follows.

$$
\begin{aligned}
& \alpha=0.015,0.025 \text { and } 0.035 \mathrm{ft}^{2} / \mathrm{h} \\
& \mathrm{T}_{\mathrm{R}}-\mathrm{T}_{\mathrm{m}}=-10,7.5,15,20 \text { and } 25^{\circ} \mathrm{F} \\
& B=3,10,20 \text {, and } 30^{\circ} \mathrm{F} \\
& \mathrm{a} \times \mathrm{b}=\begin{array}{lll}
10 \times 10 & 10 \times 6.67 & 10 \times 5 \\
15 \times 15 & 15 \times 10 & 15 \times 7.5 \\
20 \times 20 & 20 \times 13.33 & 20 \times 10 \\
30 \times 30 & 30 \times 20 & 30 \times 15
\end{array}
\end{aligned}
$$

Figure 6-1, 2, 3 shows the sample results of such calculations for $T_{\mathrm{R}}-T_{\mathrm{m}}=20^{\circ} \mathrm{F}$, and $B=30,20$ and $10^{\circ} \mathrm{F}$, respectively, for $z=1 \mathrm{ft}$. They represents the area average earth temperature 1 ft below the floor slab of $20 \mathrm{ft} x 40 \mathrm{ft}, 30 \mathrm{ft} x$ $40 \mathrm{ft}$ and $40 \mathrm{ft} \times 40 \mathrm{ft}$. These figures show a surprisingly small effect of soil thermal diffusivity upon the sub-slab temperature for all seasons, and show a larger effect of floor aspect ratio during the winter. The use of these figures for the estimation of floor heat loss, however, requires the knowledge of annual average soil temperature $T_{m}$ (which is very close to the deep underground or the well water temperature), and annual maximum and minimum monthly normal outdoor temperatures, all of which are readily available from the U.S. Weather Record Center [10]. For example, according to [9], the annual average temperature, annual maximum and minimum for the monthly normal (30-year average) data for Washington, D.C. are $56.8^{\circ} \mathrm{F}, 77.8^{\circ} \mathrm{F}$ and $36.5^{\circ} \mathrm{F}$, respectively. From this, one can arrive at $\mathrm{T}_{\mathrm{m}}=56.5^{\circ} \mathrm{F}$, and $\mathrm{B}=(77.8-36.5) / 2=20.65^{\circ} \mathrm{F}$ or say $20^{\circ} \mathrm{F}$. Using figure 6-2, one can then estimate the seasonal floor slab heat loss for the slab having temperature of $56.5+20=76.5^{\circ} \mathrm{F}$, provided that the thermal properties of the slab are very similar to those of the soil beneath the floor. If one assumes that the soil has the thermal diffusivity of $0.025 \mathrm{ft}^{2} / \mathrm{h}$, thermal conductivity $0.5 \mathrm{Btu} / \mathrm{h} \cdot \mathrm{ft} \cdot \mathrm{F}$, and the floor-slab is $30 \mathrm{ft} \times 40 \mathrm{ft}$ (aspect ratio 0.75 ), the following floor heat loss calculation can be made from figure 6-2. 


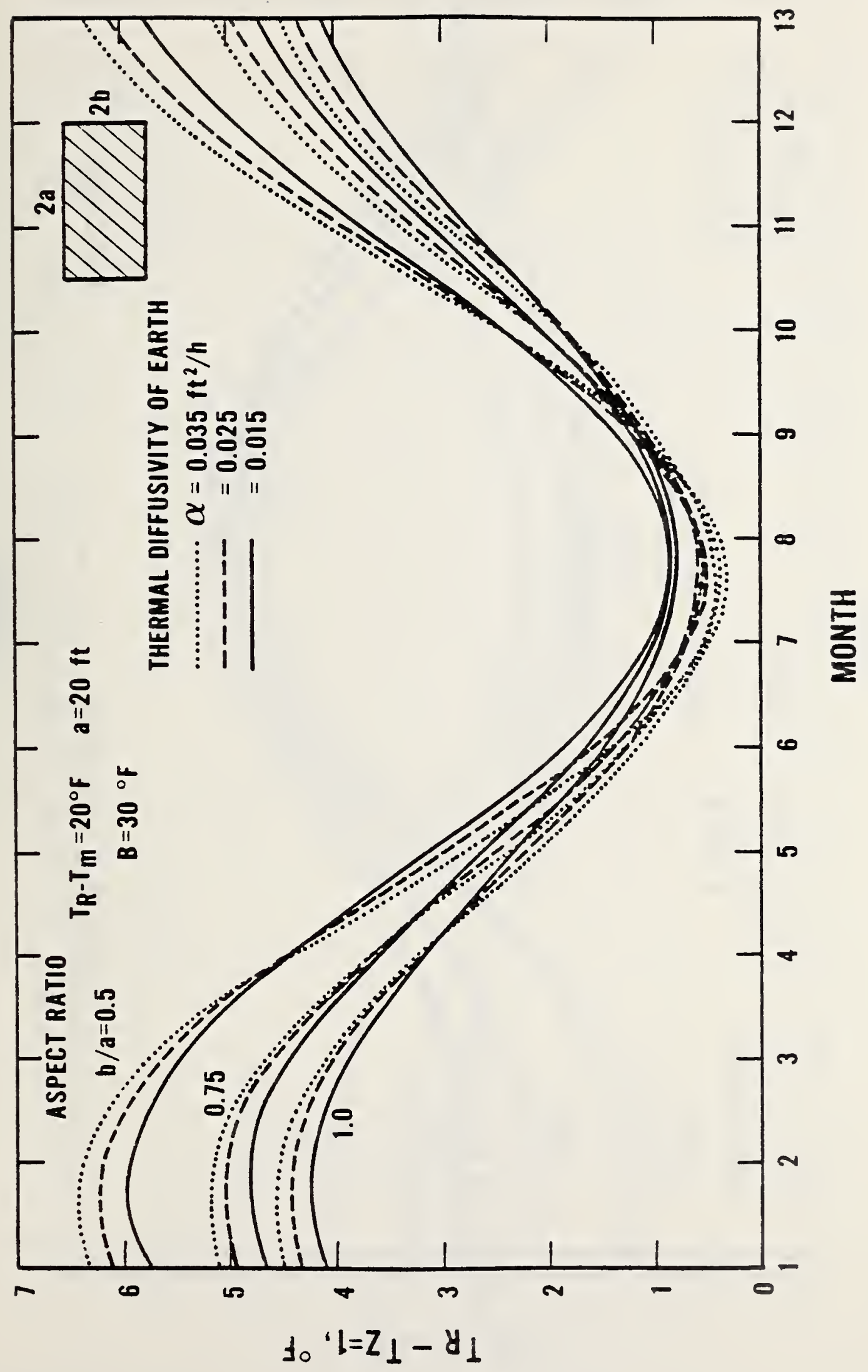

Eigure 6-1. Average earth temperature 1 ft below the floor slab for $B=30$ 


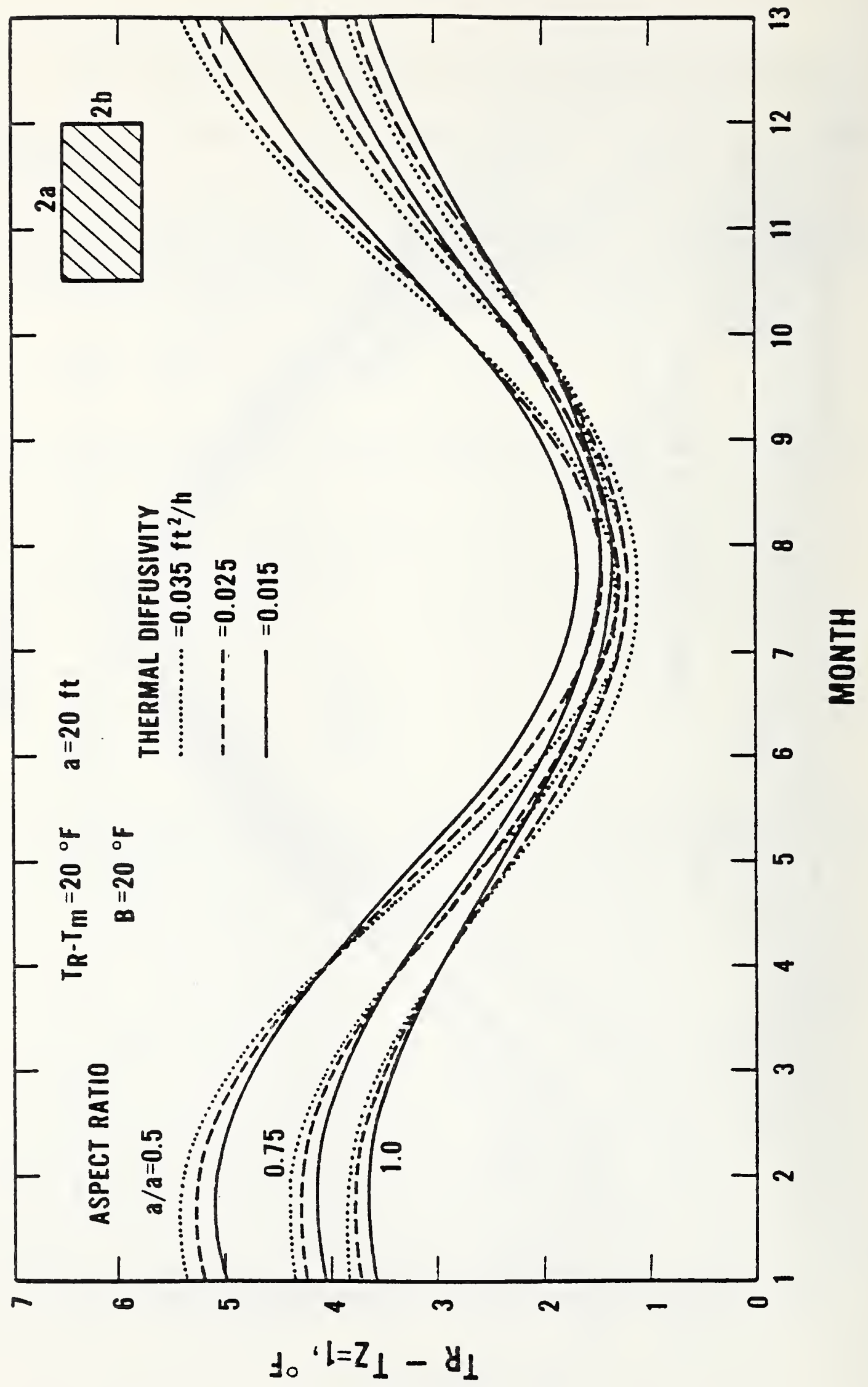

Figure 6-2. Average earth temperature 1 ft below the floor slab for $B=20$ 


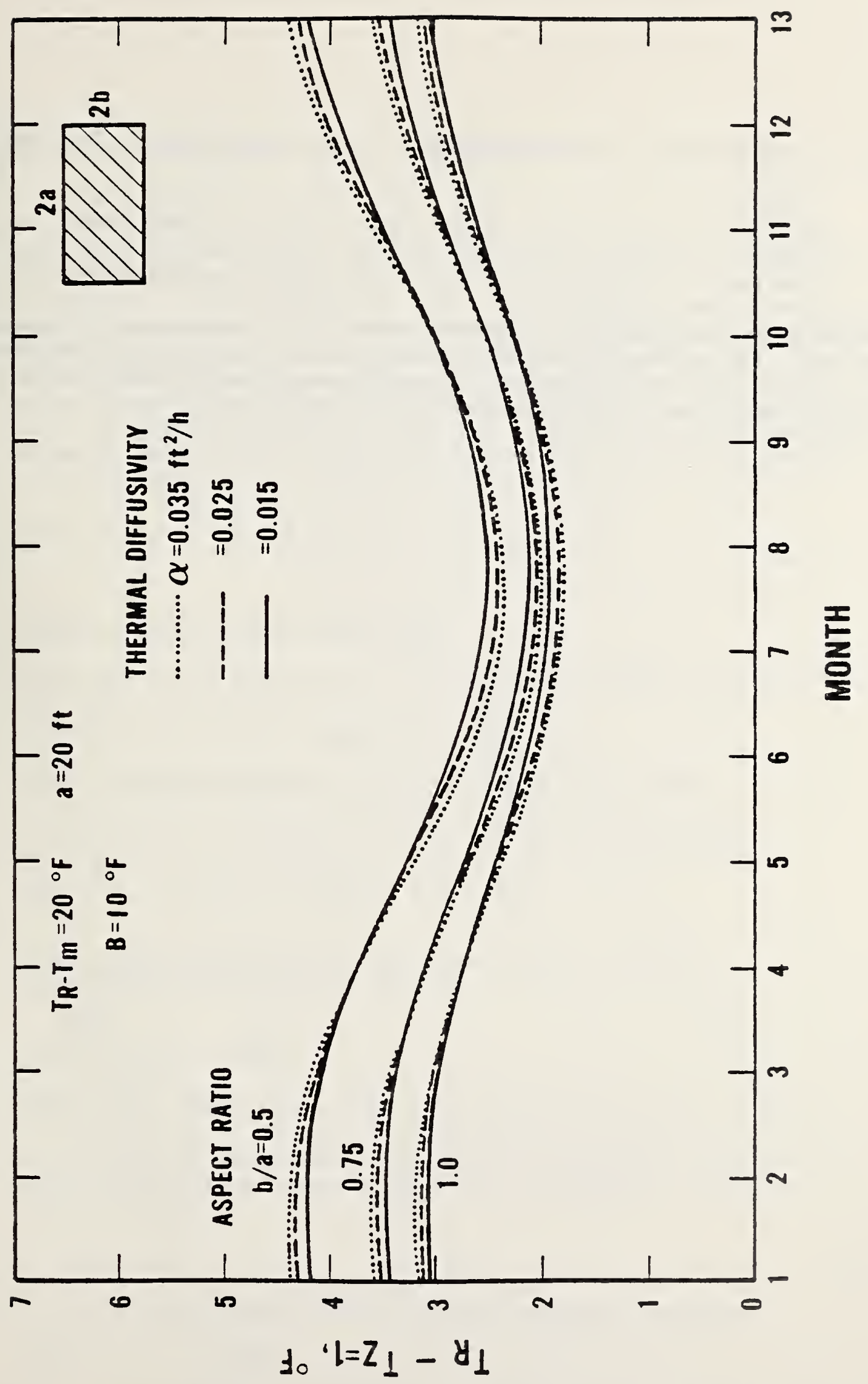

Figure 6-3. Average earth temperature 1 ft below the floor slab for $B=10$ 


\begin{tabular}{lcr} 
Month & $\mathrm{T}_{\mathrm{R}}-\mathrm{T}_{\mathrm{z}=1}$ & $\mathrm{Q}=0.5\left(\mathrm{~T}_{\mathrm{R}}-\mathrm{T}_{\mathrm{z}}\right)(1200)$ \\
\cline { 2 - 3 } & 4.3 & $2580 \mathrm{Btu} / \mathrm{h}$ \\
January & 3.4 & $2040 \mathrm{Btu} / \mathrm{h}$ \\
April & 1.3 & $780 \mathrm{Btu} / \mathrm{h}$ \\
July & 2.3 & $1380 \mathrm{Btu} / \mathrm{h}$
\end{tabular}

When the slab temperature is different from $76.5^{\circ} \mathrm{F}$, because of different house temperature and/or floor insulation, the procedure becomes more complicated. The following section describes a general procedure applicable to floor slabs having different thermal properties than the soil beneath them. 
4. SIMPLIFIED PROCEDURE FOR ESTIMATING SEASONAL HEAT LOSS FROM THE SLAB-ON-GRADE FLOOR

The seasonal heat loss calculation procedure developed herein for the slab-on-grade floor is based on the seasonal and area average soil temperature beneath the floor, room temperature, and floor system thermal conductance (inclusive of the soil layer beneath the slab). The sub-floor soil temperature data are derived from the extensive Lachenbruch-type calculations discussed in the previous sections for various combinations of floor aspect ratios, annual cycles of monthly normal temperature, and soil thermal diffusivity. Also included in the analysis is the annual cyclic variation of indoor temperature that simulates the different thermostat settings encountered during summer and winter. In the procedure derived herein, the average sub-floor temperature $\overline{\mathrm{T}}_{z}$ at a depth of $z$ is expressed in a fashion similar to equation ( 3 ), by

$$
\bar{T}_{z}=T_{m}+\left(T_{R}-T_{m}\right) \theta_{1 m}+B \theta_{2 m}^{\prime}+(C-B) \theta_{3 m}^{\prime}
$$

where

$$
\begin{aligned}
T_{\mathrm{m}} & =\text { annual average outdoor temperature } \\
B & =\text { amplitude of the annual cycle of the monthly normal temperature } \\
C & =\text { amplitude of the house temperature cycle } \\
\theta_{1 m} & =\text { annual average temperature rise function found in figure } 7
\end{aligned}
$$

$\theta$ Im may also be approximated by the following enpirical relationship

$$
\begin{aligned}
& \theta_{1 \mathrm{~m}}=e^{-\left(\frac{z}{a}\right)^{0.8}} \cdot\left\{3.312-3.324\left(\frac{b}{a}\right)+1.476\left(\frac{b}{a}\right)^{2}\right\} \\
& \theta_{2 m}=\begin{array}{l}
\text { annual cycle of undisturbed earth temperature, which is } \\
\text { determined by the following equation }
\end{array} \\
& \theta_{2 \mathrm{~m}}^{\prime}=e^{-z \sqrt{\frac{\omega}{2 \alpha}}} \sin \left(\omega t-z \sqrt{\frac{\omega}{2 \alpha}}\right) \\
& \theta_{3 m}=\text { annual cyclic temperature effect upon the sub-slab temperature. }
\end{aligned}
$$

The value for $\theta \overline{3}$ will be determined by the following equation using two factors, $\beta$ and $\psi$, which are shown in figures $8-1,8-2$, and $8-3$, for three different aspects ratios

$$
\theta \hat{3}_{\mathrm{m}}=\beta \sin (\omega t-\psi)
$$

$B$ and $\psi$ also can be approximated by the following empirical equations

$$
B=e^{-\left(\frac{z}{a}\right)^{m}}\left\{A_{1}+B_{1}\left(\frac{a^{2} w}{a}\right)^{n}\right\}
$$




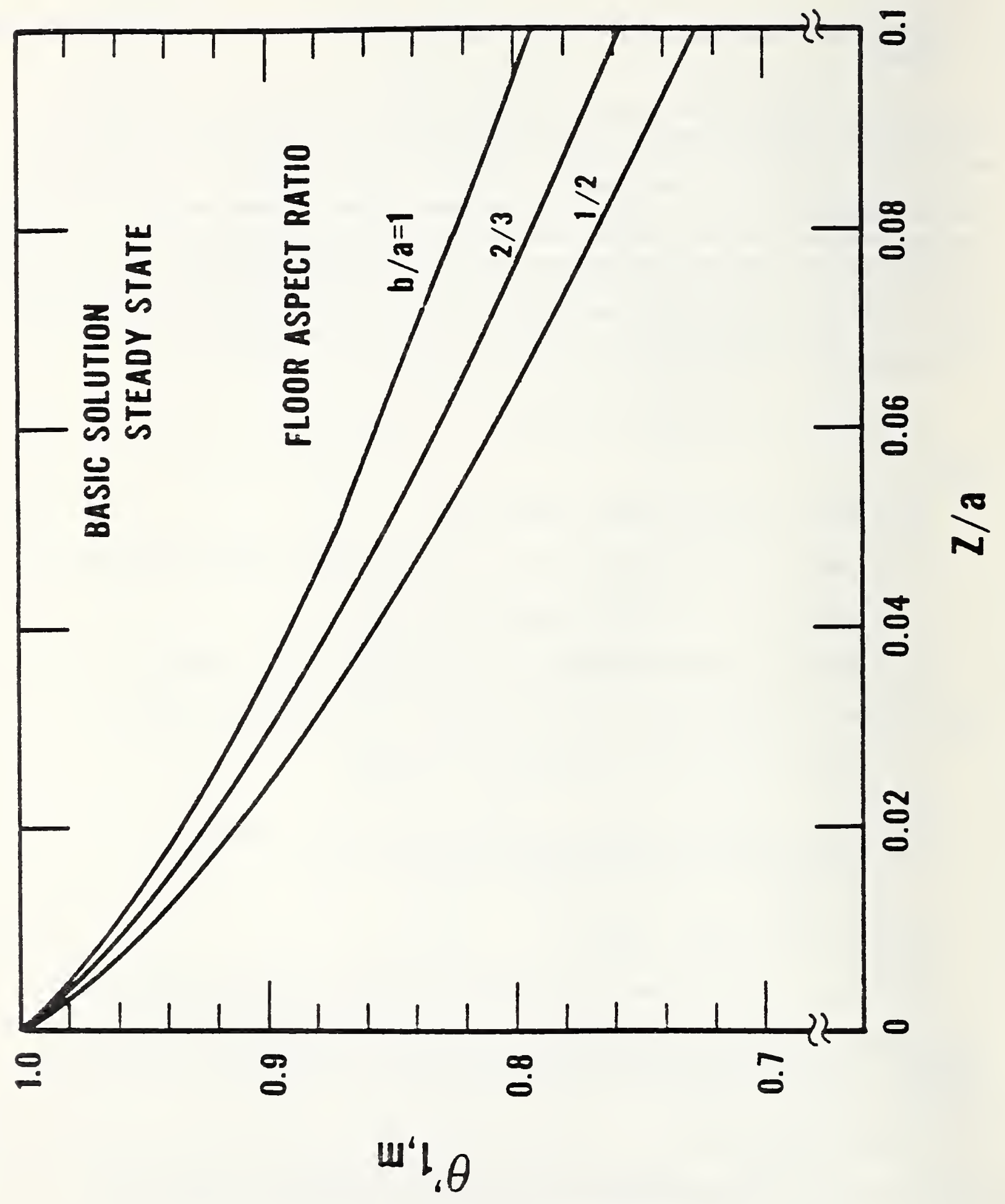

-1. Average temperature function under steady-state conditions 


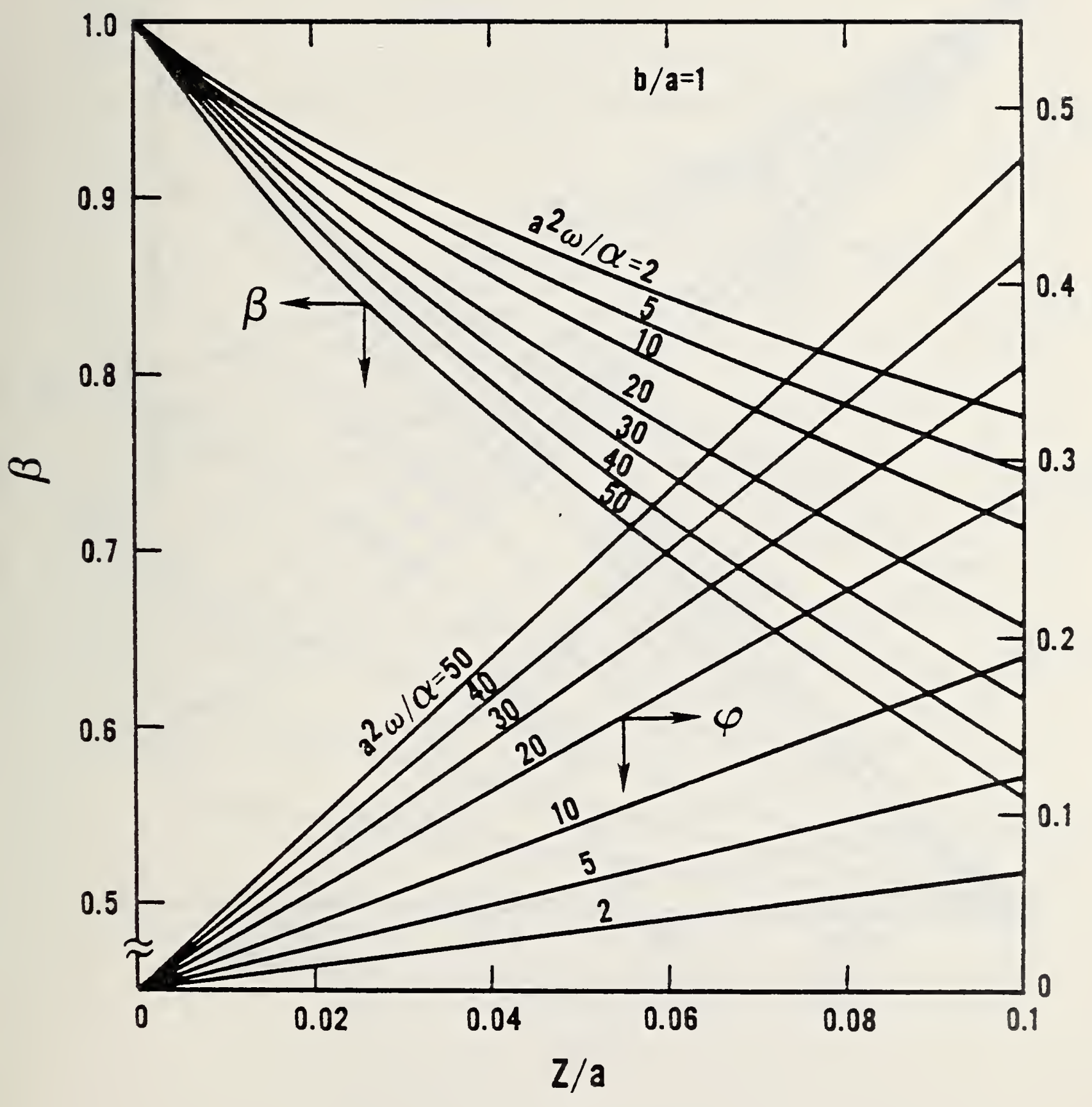

Figure 8-1. Average sub-grade temperature coefficients for the floor aspect ratio $1: 1$ 


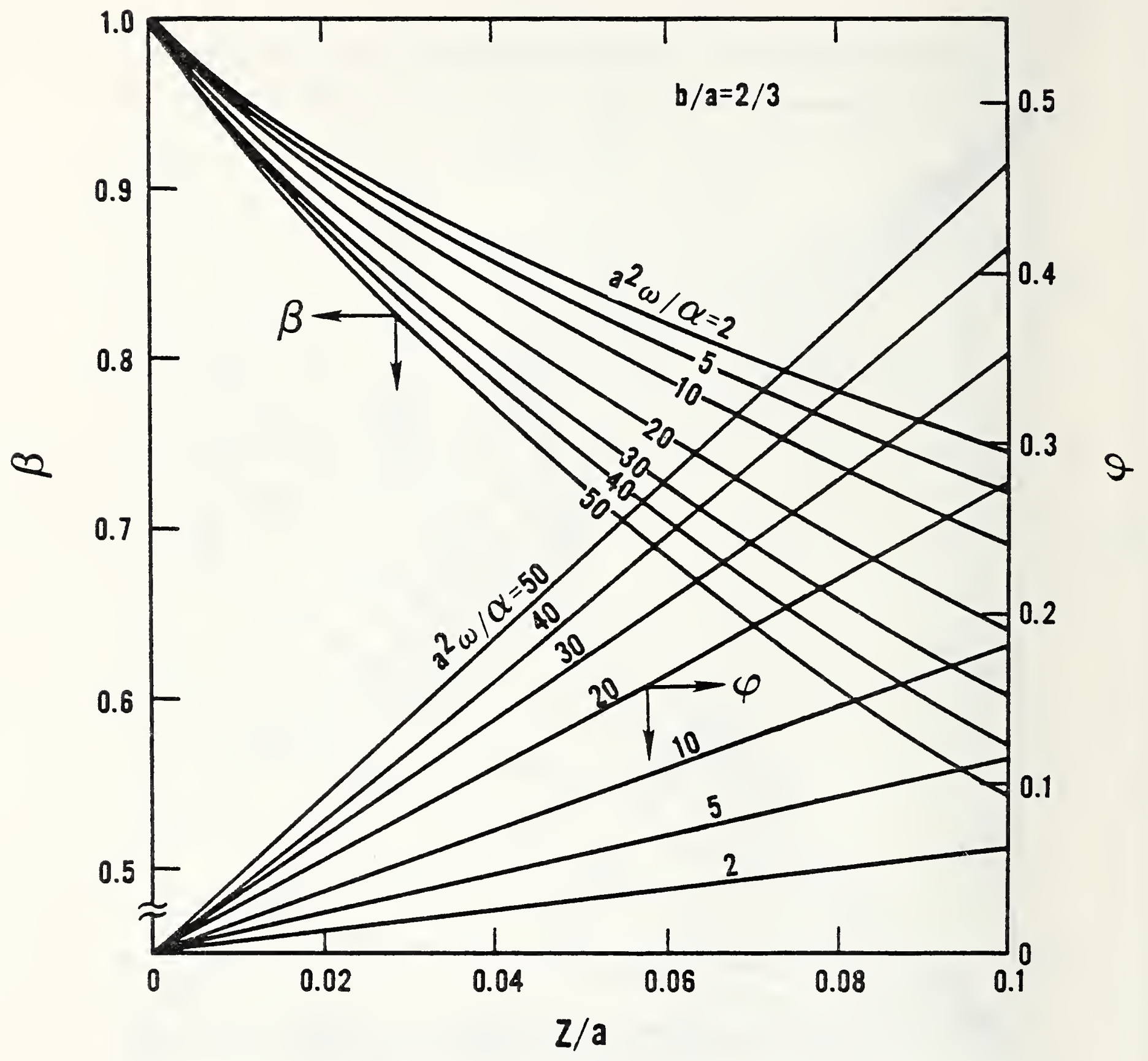

Figure 8-2. Average sub-grade temperature coefficients for the floor aspect ratio $2: 3$ 


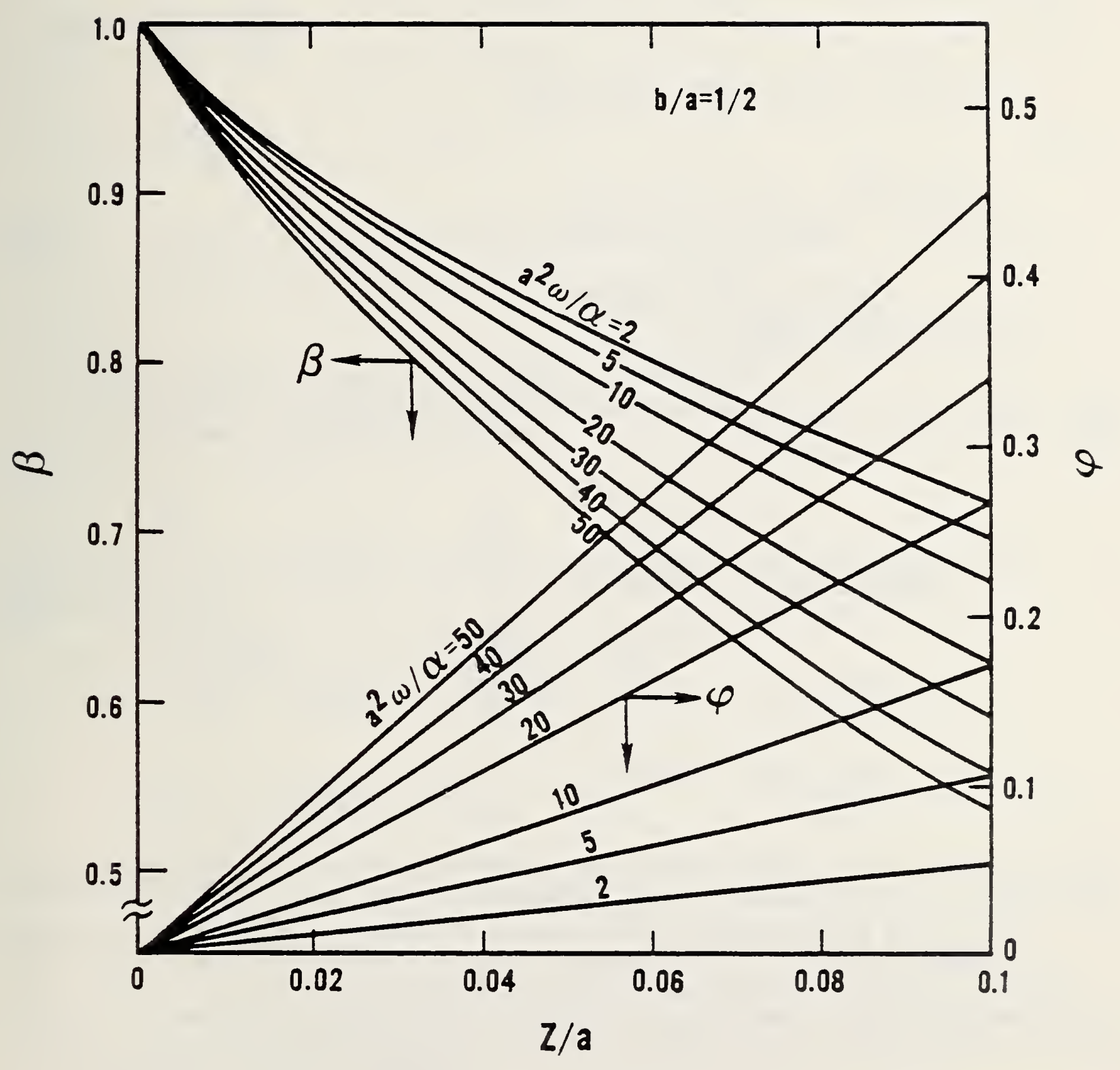

Figure 8-3. Average sub-grade temperature coefficients

for the floor aspect ratio $1: 2$ 
where $A_{1}=2.919-3.029\left(\frac{b}{a}\right)+1.362\left(\frac{b}{a}\right)^{2}$

$$
\begin{aligned}
& B_{1}=0.1957+0.0936 \frac{\left(\frac{b}{a}\right)+0.0144\left(\frac{b}{a}\right)^{2}}{n=0.6773+0.0141\left(\frac{b}{a}\right)-0.0426\left(\frac{b}{a}\right)^{2}} \\
& m=\left(\frac{a^{2} w}{\alpha}\right) \\
& n
\end{aligned}
$$

where values of $C_{1}, D_{1}, E_{1}$ and $F_{1}$ may be found in table as a function of $a^{2} w$

$\alpha$

$\begin{array}{ccccc} & C_{1} & D_{1} & E_{1} & F_{1} \\ 1.8<\frac{a^{2} w}{\alpha}<7 & 0.236 & 0.168 & 0.800 & 0.111 \\ 7<\frac{a^{2} w}{\alpha}<16 & 0.278 & 0.207 & 0.713 & 0.119 \\ 16<\frac{a^{2} w}{\alpha}<45 & 0.372 & 0.170 & 0.623 & 0.067\end{array}$

The floor heat loss is then calculated by knowing the overall thermal conductance $U_{G}$ of the soil layer of thickness \& such that

$$
Q=U_{G}\left(T_{R}-\bar{T}_{z}\right) A
$$

and $U_{G}=\frac{k}{l}$.

\section{Insulated slab-floor}

While the preceding analysis assumes that the floor slab has the same thermal properties as those of the soils below (which is approximately correct for uninsulated concrete floor over relatively wet soil), many floor systems include thermal insulation with their thermal property data being considerably different from those of the sub-soil. When dealing with an insulated floor, one must account for an appreciable temperature drop across it. Thus the values of $T_{R}$ 
and $C$ in equation ( 7 ) must be adjusted to take this fact into account. A suggested method is to estimate them by the following equations:

$$
\begin{aligned}
& T_{R}^{\prime}=\frac{U_{F} T_{R}+U_{G} \bar{T}_{z}}{U_{F}+U_{G}} \\
& C^{\prime}=\frac{U_{F} C}{U_{F}+U_{G}}
\end{aligned}
$$

where $T_{R}^{\prime}=$ annual average temperature of soil-floor interface

$$
\begin{aligned}
& C^{\prime}=\text { amplitude of the annual cycle of soil-floor interface } \\
& \begin{aligned}
U_{F} & =\text { insulated floor system thermal conductance } \\
U_{G} & =\text { subsoil thermal conductance } \\
& =\frac{k}{z}
\end{aligned}
\end{aligned}
$$

Substituting $T_{R}{ }^{\prime}$ and $C^{\prime}$ for $T_{R}$ and $C$ of equation (7), and rearranging the terms, one obtains

$$
\begin{aligned}
\overline{\mathrm{T}}_{z}= & \frac{U_{F}+U_{G}}{U_{F}+U_{G}\left(1-\theta_{1 m}^{-}\right)}\left[T_{m}+\left(\frac{U_{F} T_{R}}{U_{F}+U_{G}}-T_{m}\right)_{1 m}^{-}\right. \\
& \left.+B \theta_{2 m}^{-}+\left(\frac{U_{F} C}{U_{F}+U_{G}}-B\right) \theta_{3 m}^{-}\right]
\end{aligned}
$$

\section{Sample Calculations}

Determine the January and August heat loss from a slab-on-grade floor of a $40 \mathrm{ft} \times 30 \mathrm{ft}$ house in Washington, D.C. Assume that the floor is carpeted with underlay over the 4-in concrete slab, and that soil is of medium moisture content. In addition, assume that l-in polystyrene thermal insulation board is placed between the soil and concrete slab. The house is thermostated at $78^{\circ} \mathrm{F}$ in summer and $68^{\circ} \mathrm{F}$ in winter. 
1. Floor system thermal resistance

inside surface resistance
carpet
underlay
4" concrete
l" polystyrene board

$U_{F}=\frac{1}{6.8}=0.147$

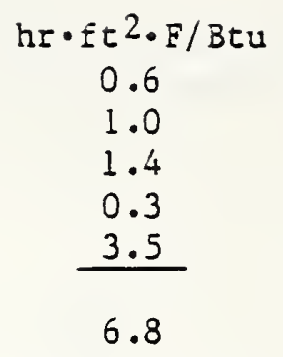

0.6

1.0

1.4

0.3

3.5

6.8

$B t u / h r \cdot f t^{2} \cdot F$

2. Assume soil thermal property as follows:

thermal conductivity $k=0.5 \mathrm{Btu} / \mathrm{hr} \cdot \mathrm{ft} \cdot \mathrm{F}$

thermal diffusivity $\alpha=0.025 \mathrm{ft}^{2} / \mathrm{h}$

or $U_{G}=0.5 \mathrm{Btu} / \mathrm{hr} \cdot \mathrm{ft} \cdot \mathrm{F}$ for $z=1 \mathrm{ft}$

3. Surface temperature condition (see previous example)

$T_{\text {m }}=56.5^{\circ} \mathrm{F}$

$B^{2}=20.65^{\circ} \mathrm{F}$

4. Indoor temperature condition

$T_{R}=(78+68) / 2=73$

$C=(78-68) / 2=5$

5. Since $2 a=40,2 b=30, a=20$ and $b=15$

aspect rates $b / a=15 / 20=0.75$

depth parameter $z / a=1 / 20=0.050$

$\theta_{\text {lm }}^{-}=0.85$ from figure 7 .

6. Elapsed time after April 1 will be

$$
\begin{aligned}
\omega t= & \frac{2 \pi}{365}(275)=4.73 \text { for January } 1 \\
& \frac{2 \pi}{365}(122)=2.100 \text { for August } 1 \\
z \sqrt{\frac{\omega}{2 \alpha}}= & (1) \sqrt{\frac{2 \pi}{365 \times 0.025 \times 24}}=0.170
\end{aligned}
$$




$$
\begin{aligned}
\theta_{2 m}^{-} & =e^{-0.17} \sin (4.73-0.17)=-0.834 \text { for January } 1 \\
& =e^{-0.17} \sin (2.10-0.17)=0.790 \text { for August } 1
\end{aligned}
$$

7. $\frac{a^{2} w}{\alpha}=\frac{(20)^{2\left(\frac{2 \pi}{365}\right)}}{0.025 \times 24}=11.5$

from figure $8-2$ for $z / a=0.050$

$$
\begin{aligned}
& B=0.84 \\
& \psi=0.10
\end{aligned}
$$

8. Using equation ( 9 )

$$
\begin{aligned}
\theta_{3 \mathrm{~m}}^{-} & =0.81 \sin (4.73-0.10)=-0.807 \text { for January } 1 \\
& =0.81 \sin (2.11-0.10)=0.733 \text { for August } 1
\end{aligned}
$$

9. $\frac{U_{E} T_{R}}{U_{F}+U_{G}}=\frac{(0.147)(73)}{0.147+0.5}=16.6$

$$
\begin{aligned}
& \frac{U_{F} C}{U_{F}+U_{G}}=\frac{(0.147)(5)}{0.147+0.5}=1.14 \\
& \frac{U_{F}+U_{G}}{U_{F}+U_{G}\left(1-\theta_{1 m}^{\prime}\right)}=\frac{0.147+0.5}{0.147+0.5(1-0.85)} \\
&=\frac{0.647}{0.222}=2.91
\end{aligned}
$$

10. For January 1

$$
\begin{aligned}
\overline{\mathrm{T}}_{z=1}= & 2.91[56.5+(16.6-56.5)(0.85)+(20.65)(-0.834) \\
& +(1.14-20.65)(-0.807)] \\
= & 2.91[56.6-33.9-17.2+15.74] \\
= & 2.91[21.14]=61.5^{\circ} \mathrm{F}
\end{aligned}
$$


For August 1

$$
\begin{aligned}
T_{z=1}= & 2.91[56.5+(16.6-56.5)(0.85)+(20.65)(0.79) \\
& +(1.14-20.65)(0.733)] \\
= & 2.91[56.5-33.9+16.31-14.30] \\
= & (2.91)(24.61)=71.6
\end{aligned}
$$

11. House temperature

January $1: 73+5 \sin (4.73)=68^{\circ} \mathrm{F}$

August $1: 73+5 \sin (2.10)=79^{\circ} \mathrm{F}$

12. Floor/soil thermal conductance

$\frac{1}{U}=\frac{1}{U_{F}}+\frac{1}{U_{G}}=6.8+2=8.8$

$U=0.1136$

13. Floor heat loss is then

January : $(0.11367)(68-61.5)(1200)=886 \mathrm{Btu} / \mathrm{h}$

August : $(0.1136)(77-71.8)(1200)=736 \mathrm{Btu} / \mathrm{h}$

If similar calculations are performed for the non-insulated slab floor whereby the slab thermal properties are nearly equal to those of the soil below, equation (7) may be used directly to find the sub-soil temperature 1 ft below the floor surface as follows.

January 1 :

$$
\begin{aligned}
\mathrm{T}_{z=1} & : 56.5+(73-56.5)(0.85)+(20.65)(-0.834)+(5-20.65)(-0.807) \\
& =56.5+14.03-17.22+12.63=65.9
\end{aligned}
$$

For August 1:

$$
\begin{aligned}
T_{z=1} & : 56.5+(73-56.5)(0.85)+(20.65)(0.79)+(5-20.65)(0.733) \\
& =56.5+14.03+16.30-11.47=75.4
\end{aligned}
$$

The floor heat loss would then be

for January $:(0.5)(68-65.9)(1200)=1260 \mathrm{Btu} / \mathrm{h}$

for August : $(0.5)(77-75.4)(1200)=960 \mathrm{Btu} / \mathrm{h}$ 
These calculations show that the subfloor temperature is lower when the floors are insulated than otherwise. Comparison of the uninsulated floor heat loss

with that determined by the ASHRAE Handbook equation could yield

$$
q=(0.81)(140)(68-36.5)=3572 \mathrm{Btu} / \mathrm{h}
$$

when the winter outdoor temperature is assumed $36.5^{\circ} \mathrm{F}$. 


\section{SUMMARY AND DISCUSSION}

Monthly depth profiles of the earth temperature beneath the floor slab have been determined by using the Lachenbruch method. The results were used to develop a simplified procedure for calculating the area average temperature beneath the slab floor area. The area-averaged earth temperature can in turn be used to approximate the monthly floor heat loss. In addition, the area-averaged subfloor earth temperature determined by this method should be good reference data for the response factor-type evaluation of hourly floor heat transfer.

Caution must be exercised, however, for the use of average sub-floor soil temperatures in the calculation of the floor heat loss, because the method ignores several important facts.

1. The floor foundation effect: The floor slab is usually mounted on a concrete foundation of complex shape around its edge. These concrete foundations could cause additional complexity in the temperature field around the floor slab because of differences in thermal conductivity from the surrounding soil.

2. The edge insulation: Some slab-on-grade floors employ insulation around their edges, which would yield different temperature fields than predicted by the procedure developed in this paper.

3. Building wall thickness effect: The analysis employed in the proposed procedure assumes that the slab temperature is uniform from one end of the floor to another, and assumes an abrupt temperature drop at the edge from the indoor condition to outdoor condicion. In reality, the slab temperature would undergo a gradual change near the edge, and the transition temperature profile from the indoor condition to the outdoor condition depends heavily upon the thickness and thermal characteristics of the wall over the slab edge. If the wall is thicker and better insulated, the temperature transition would be steeper than the thinner and poorly insulated wall.

The Lachenbruch procedure employed in this paper could simulate the nonuniform slab temperature as long as its profile is known. Muncey/ Spencer [6] relation can indeed take into account the building wall problem by assuming prescribed slab-to-outdoor temperature distribution functions.

One of the dubious aspects of this area-averaged sub-floor earth temperature concept is that the depth for which the area averaging is to be performed is not well defined. If the depth is too great, the edge heat loss effect will not be adequately reflected. On the other hand, if the depth is too small, the edge effect will be overated with the reason discussed above, in reference to the wall thickness effect. In fact, a preliminary result of the heat flux measurement on the NBS test house (in Gaithersburg, MD) during January of 1981, indicated that the edge effect on a $20 \mathrm{ft} x 20 \mathrm{ft}$ slab-on-grade house is not as severe as that calculated by equation (4). It appears that the use of areaaveraged earth temperatures 1 ft below the slab provides a good base for the saasonal slab-heat-loss calculation, although further and detailed validation ffort is needed. 


\section{REFERENCES}

1. Chapter 24, "Heating Load," Handbook of Fundamentals, ASHRAE, page 24.4, 1977.

2. R. S. Dill, W. C. Robinson, and H. E. Robinson, "Measurements of Heat Losses from Slab Floors," NBS Building Material and Structures Report BMS 103, March 1943.

3. H. D. Bareither, A. N. Fleming, and B. E. Alberty, "Temperature and Heat Loss Characteristics of Concrete Floors Laid on the Ground," University of Illinois Small Homes Council Technical Report, PB 93920, 1948.

4. A. H. Lachenbruch, "Three Dimensional Heat Conduction in Permafrost Beneath Heated Buildings," Geological Survey Bulletin 1052-B, U.S. Government Printing Office, Washington, D.C., 1957.

5. B. Adamson, "Soil Temperature Under Houses Without Basements," Byggforskningen Handinger, Nr 46 Transactions, 1964.

6. R. W. R. Muncey and J. W. Spencer, "Heat Flow into the Ground Under a House," Energy Conservation in Heating, Cooling, and Ventilating Buildings, Hemisphere Publishing Corporation, Washington, D.C., Vol. 2, Pp. 649-660, 1978.

7. H. Akasaka, "Calculation Methods of the Heat Loss Through a Floor and Basement Walls," Transactions of the Society of Heating, Air-Conditioning, and Sanitary Engineers of Japan, No. 7, pp. 21-35, June 1978.

8. T. Kusuda, "Review of Current Calculation Procedures for Building Energy Analysis," National Bureau of Standards NBSIR 80-2068, July 1980.

9. T. Kusuda, "Thermal Response Factors for Multi-Layer Structures of Various Heat Conduction Systems" ASHRAE Transactions, pp. 250-269, Part I, 1969.

10. , Monthly Normal Temperatures, Precipitations and Degree Days," U.S. Weather Bureau, U.S. Department of Commerce, Washington, D.C., 1956. 



\section{APPENDIX A}

\section{Muncey/Spencer Solution}

In 1977, Muncey/Spencer published a result of many years' work [6] that involves the frequency domain or Fourier series solution of the same differential equation which was solved by Lachenbruch by Green's Function [4]. The following equations show the Muncey/Spencer representations of slab surface temperature, slab heat flux, $Q$, and room temperature above the slab, $X$, respectively:

$$
\begin{aligned}
& V=\frac{T(x, y, 0, \theta)}{T_{R}}=\Sigma \Sigma T_{m, n} \cos \left(\frac{\pi m x}{f u}\right) \cos \left(\frac{\pi n y}{g v}\right) e^{j \omega \theta} \\
& Q(x, y, 0, \theta)=\Sigma \Sigma W_{m, n} \cos \left(\frac{\pi m n}{f u}\right) \cos \left(\frac{\pi n y}{g v}\right) e^{j \omega \theta}=\frac{1}{R_{a}}[x-V]
\end{aligned}
$$

where $R_{a}=$ thermal resistance of the slab surface

$$
x(x, y, 0, \theta)=\Sigma \Sigma \quad z_{m, n} \cos \left(\frac{\pi m x}{f u}\right) \cos \left(\frac{\pi n y}{g v}\right) e^{j \omega \theta}
$$

where $u, v, f$ and $g$ are defined graphically in figure $A-1$.

Moreover, it was recommended that the summation of Fourier terms be carried out for $m$ and $n$ from 1 through up to 16 .

The integrated average floor heat loss is then

$$
\begin{aligned}
q & =\int_{-v}^{v} \int_{-u}^{u} Q(X, Y, O, \theta) d x d y \\
& =\sum_{m n} W_{m, n} \cos \left(\frac{\pi m x}{f u}\right) \cos \left(\frac{\pi n y}{g v}\right)^{j \omega \theta} \\
& \left.=\frac{W_{0,0}}{f g}+\sum_{m=1}^{16} 2 W_{m, 0} \frac{\sin \frac{\pi m}{f g}}{\frac{\pi m}{f}}\right)^{2}+\sum_{n=1}^{16} \frac{2 W_{0, n}}{f g}\left(\frac{\sin \frac{\pi n}{g}}{\frac{\pi n}{g}} 2\right. \\
& +\sum_{n=1}^{16} \sum_{n=1}^{16} \frac{4 W_{m, n}}{f g}\left(\frac{\sin \frac{\pi m}{f}}{\frac{\pi m}{f}}\right)^{2}\left(\frac{\sin \frac{\pi n}{g}}{\frac{\pi n}{g}} 2\right.
\end{aligned}
$$

where

$$
W_{m, n}=\frac{\sqrt{\left(\frac{\pi m}{f u}\right)^{2}+\left(\frac{\pi n}{g v}\right)^{2}+j \frac{w \rho c}{k} k \cdot z_{m}, n}}{1+\sqrt{\left(\frac{\pi m}{f u}\right)^{2}+\left(\frac{\pi n}{g v}\right)^{2}+j \frac{\omega \rho c}{k} k \cdot R_{a}}}
$$




$$
\begin{aligned}
z_{0,0} & =\frac{1}{f g} \\
z_{m, 0} & =\frac{2}{\pi m g} \sin \left(\frac{\pi m}{f}\right) \\
z_{0, n} & =\frac{2}{\pi n f} \sin \left(\frac{\pi m}{g}\right) \\
z_{m, n} & =\frac{4 m n}{\pi^{2}} \sin \left(\frac{\pi m}{f}\right) \sin \left(\frac{\pi n}{g}\right) \\
\alpha & =\frac{k}{c 0} \text { or } \frac{\omega c 0}{k}=\frac{\omega}{\alpha} \\
j & =\sqrt{-1}
\end{aligned}
$$

The heat flux solution $(A-4)$, which is also the overall heat transfer coefficient between the in- and outdoor temperature, was obtained on the basis that room temperature $X$, instead of the slab surface temperature $V$, was kept constant over the slab, or $-u \leq x \leq u$ and $-v \leq y \leq v$ (Figure $A-1$ ).

Applying the solution (A-4) into many different slab programs, Muncey and Spencer were able to develop a standard slab thermal resistance curve $R_{S}$, such as shown in Figure A-2, for a $10 \mathrm{~m} \times 10 \mathrm{~m}$ square slab on the soil having thermal conductivity of $1 \mathrm{~W} / \mathrm{m} \cdot \mathrm{K}$. This $R_{S}$ can be used to determine the thermal resistance $R$ of other slabs by the following relationship:

$$
R\left(\beta k, \alpha P, \ell, R_{a}\right)=F \cdot\left(\frac{\alpha}{\beta}\right) R_{s}\left(k, P, \ell, \frac{R_{a B}}{\alpha}\right)
$$

where

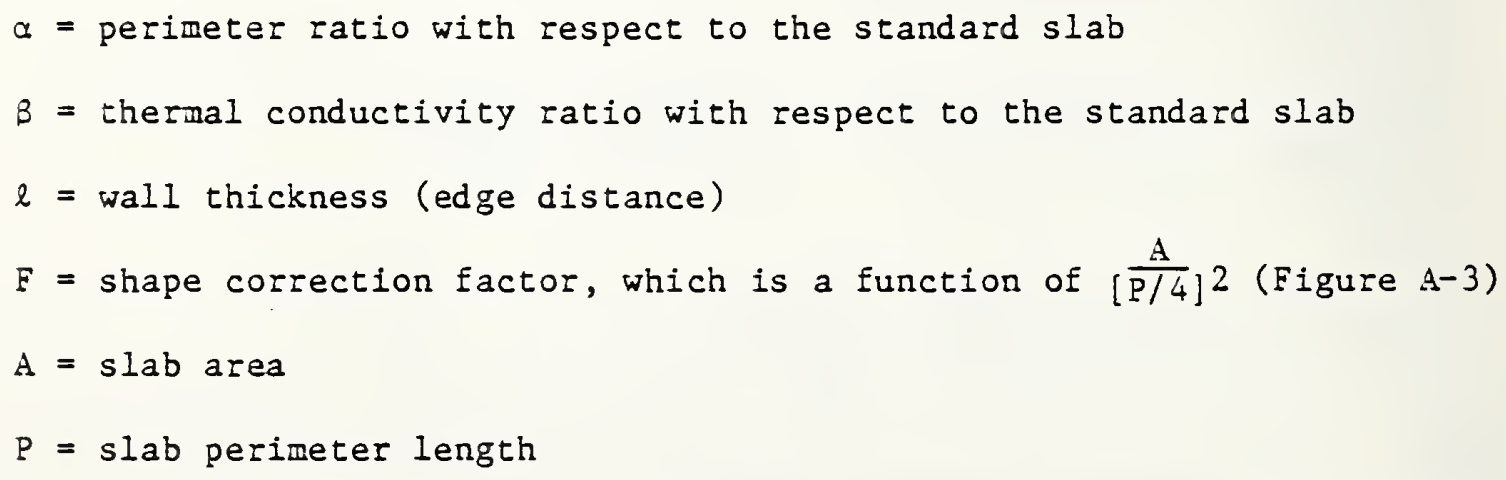

This particular Muncey/Spencer solution is, however, not applicable for the evaluation of seasonal slab-on-grade heat transfer. 


\section{MUNCEY/SPEMCER SYSTEM}

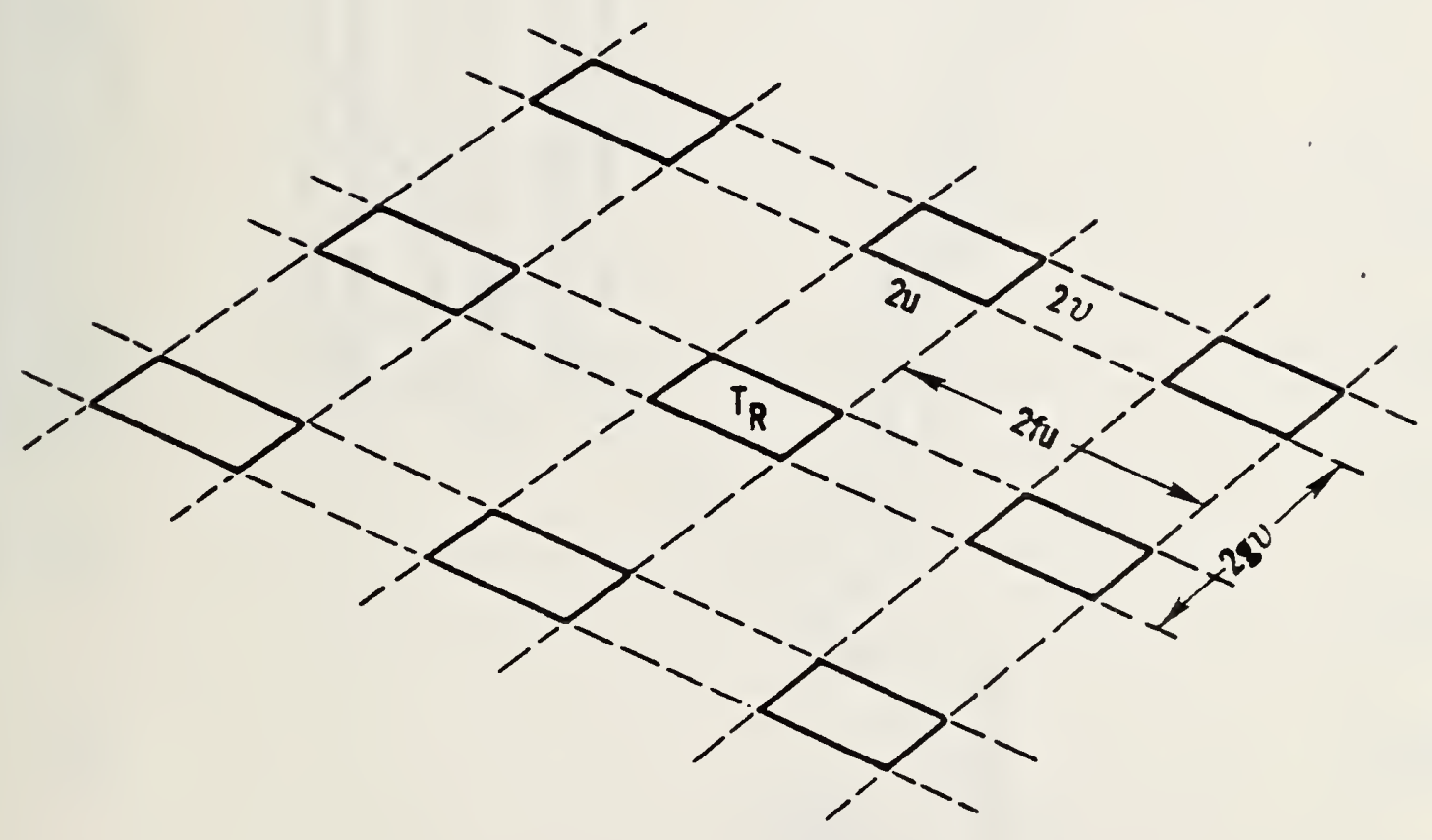

Figure A-1. Muncey/Spencer slab model $5 /$ 

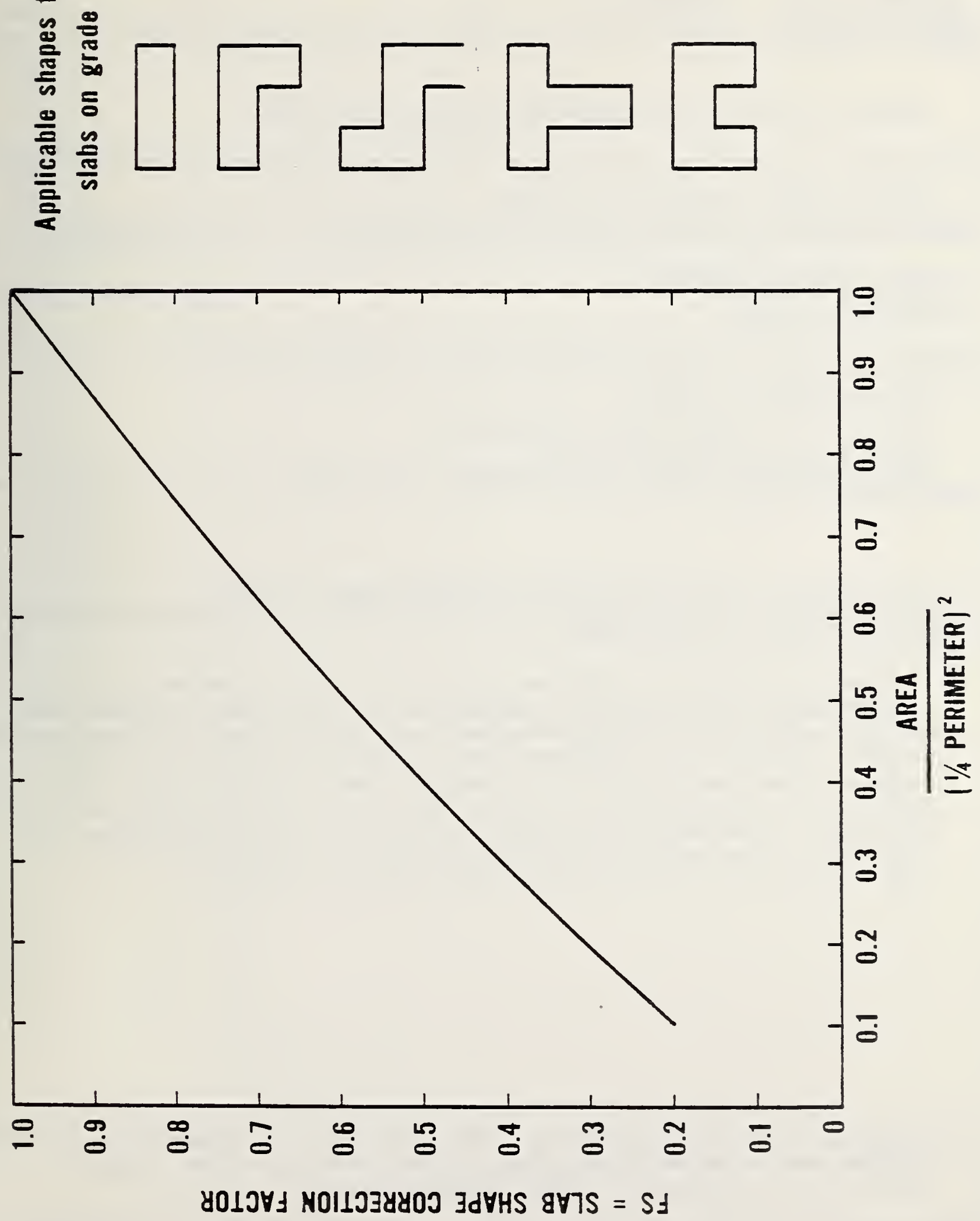

Figure A-3. Correction factor for non-square slabs 
4. TITLE AND SUBTITLE

\section{SEASONAL HEAT LOSS CALCULATION FOR SLAB-ON-GRADE FLOORS}

5. AUTHOR(S)

Tamami Kusuda; M. Mizuno; J.W. Bean

6. PERFORMING ORGANIZATION (If joint or other than NBS. see instructions)

MATIONAL BUREAU OF STANDARDS

DEPARTMENT OF COMMERCE

WASHINGTON, D.C. 20234

9. SPONSORING ORGANIZATION NAME AND COMPLETE ADDRESS (Street. City. State, ZIP)

U.S. Department of Energy

Office of Solar Application for Buildings

Conservation and Renewable Energy

1000 Independence Avenue, SW - Washington, DC 20585

10. SUPPLEMENTARY NOTES

Document describes a computer program; SF-185, FIPS Software Summary, is attached.

11. ABSTRACT (A 200-word or less factual summary of most significant information. If document includes a significant bibliography or literature survey, mention it here)

In order to facilitate an efficient slab-on-grade heat transfer calculation on a comprehensive energy analysis program such as DoE-2, BLAST and NBSLD, heat transfer calculations for slab-on-grade floors are reviewed. The computational procedure based on the Lachenbruch method is studied in depth to generate monthly average temperatures at a given depth below the floor slab. The data generated by the Lachenbruch method are then used to develop a simplified procedure for determining the monthly average earth temperatures below the floor slab. These monthly average temperature data can be used for the hourly response factor analysis of floor-slab heat transfer.

12. KEY WOROS (Six to twelve entries: alphabetical order: capitalize only proper names; and separate key words by semicolons) Building heat transfer; DoE-2 Energy Analysis computer program; monthly average earth temperature; thermal response factors.

13. AVAILABILITY

\section{Unlimited}

For Official Distribution. Do Not Release to NTIS

Order From Superintendent of Documents, U.S. Government Printing Office, Washington, D.C. 20402.

Order From National Technical Information Service (NTIS), Springfield, VA. 2216I

14. NO. OF PRINTED PAGES 49

15. Price $\$ 7.50$ 
